\title{
The Flow of Fluids through Commercial Pipe Lines ${ }^{1,2}$
}

By Robert E. Wilson, ${ }^{3}$ W. H. McAdams and M. Seltzer

Research Laboratory of Applied Chemistry, MassachusetTs Institute of Technology, Cambridge, Mass.

The information at hand concerning the flow of fluids in pipe lines is discordant, scattered, and incomplete except in a few special fields. The great bulk of the work to date has been devoted to the flow of water, from which empirical relationships and constants have been derived, but even in this case a study of the results reveals considerable disagreement among the investigators. Another range which has been carefully studied is the flow of viscous liquids, such as heavy oils and glycerol, through comparatively small tubes. Comparatively little reliable experimental. work has been published on the flow of very viscous liquids through commercial pipes, and practically none has touched on the frictional resistance of elbows in viscous flow.

Certain general principles with regard to the flow of fluids are, of course, generally recognized. Thus it is well known that there are two general types of motion for liquidsusually called viscous and turbulent flow. Viscous flow is characteristic of low velocities, small pipes, or very viscous liquids. In this form of motion, all the particles move in lines parallel to the movement of the mass as a whole, though the velocity of motion drops off rapidly from a maximum at the center to zero at the outside of the pipe. The average velocity over the entire cross-section of the pipe is one-half the maximum value at the center of the pipe. ${ }^{5}$ This form of motion is shown graphically in Fig. 1. It is to be noted that there are no "cross" or mixing currents. It is well established that Poiseuille's formula holds for this type of motion. Expressed in convenient engineering units, this takes the modified form: ${ }^{6}$

$$
p=\frac{0.000668 z l v}{D^{2}}
$$

In the case of every fluid, as the velocity is increased a point is eventually reached where a rapid transition takes place from viscous flow to an eddying, mixing type of motion known as turbulent flow, and here the net velocity distribution curve is much flatter, the average velocity being about 80 per cent of that at the center. (See Fig. 1.) The transition velocity is called the critical velocity and its magnitude depends upon the viscosity and density of the liquid and the size (and roughness) of the pipe (increasing in direct proportion to the first factor, and in inverse proportion to the other two).

The formula most frequently used for turbulent flow is that of Fanning, which in engineering units can be expressed:

$$
p=\frac{0.323 f l s v^{2}}{\mathrm{D}}
$$

It will be noted that the principal differences between the formulas for viscous and turbulent flow are that in the latter

1 Received December 10, 1921.

2 Published as Contribution No. 40 from the Research Laboratory of Applied Chemistry, Massachusetts Institute of Technology.

- Director, Research Laboratory of Applied Chemistry, M. I. T,

- Assistant Professor of Chemical Engineering, M. I. T.

$s$ This may be proved mathematically, from the definition of absolute viscosity (see Lamb, "Hydromechanics of Fluids," 1916) and has been verified experimentally by Stanton and Pannell [Collected Researches, National Physical I aboratory, Teddington, England, 11 (1914)],

6 The following nomenclature is used throughotit this paper:

$f=$ friction factor (Fanning) $\quad s$ specific gravity of liquid

$l=$ length of pipe $(\mathrm{ft}) \quad D=$. inside pipe diameter (in.)

$v=$ average linear velocity in pipe $Q=$ flow (gal./min.) line (ft./sec.)

$z=$ viscosity in centipoises ( $=$ metit of these quantities is discussed relative to water at $68^{\circ} \mathrm{F}$.) later.

$\phi=$ pressure drop (lbs./sq.in.) case the velocity occurs as the square rather than the first power, while the diameter of the pipe occurs as the first power rather than the square. Furthermore, the viscous flow formula includes the viscosity of the fluid as one factor and does not require any variable coefficient, while the turbulent flow formula apparently disregards the viscosity of the liquid, and adds a variable friction factor, $f$, which is a rather complicated function of velocity, pipe diameter, viscosity, density, and the condition of the pipe surface.

It is thus apparent that the above formula for turbulent flow is only a rough approximation of its true law of motion, and the results can be made accurate only by varying the values used for the friction factor $f$. Attempts to formulate a general equation have resulted in the use of fractional

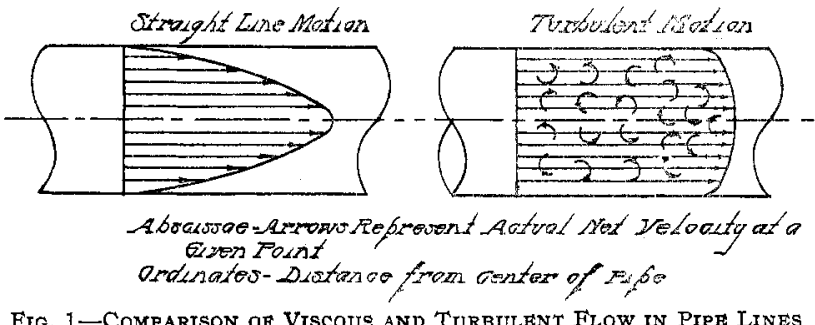

exponents for $v$ and $D$, but no two writers agree as to the exact magnitude of the exponents, except to place that of $v$ generally between 1.6 and 1.9 , and that of $\mathrm{D}$ between 1.4 and. 1.1. These attempts have failed, since these exponents hold approximately constant only over a limited range of velocity and diameter. Corrections for roughness are also a disturbing factor. One or two writers suggest putting $z$ into the numerator of Fanning's equation with a small fractional exponent in the neighborhood of 0.4 . The diffculty of using such equations in practical work is obvious.

The object of the experimental work described herein was to fill in the gaps in the existing data on the flow of fluids in pipes of commercial size and roughness, especially for very viscous liquids and in the critical region between viscous and turbulent flow; and to determine with reasonable accuracy correction factors for the pressure drop around bends. By combining these data with a critical survey of existing information, it has been found possible to develop a simple but comprehensive method of treatment of the whole subject of the flow of all types of fluids through commercial pipe lines, using a single method of calculation for all types of flow.

This work was undertaken at the instigation of Dr. W. K. Lewis and has profited greatly by his suggestions and advice. Acknowledgments are also due to the National Tube Company, who supplied most of the pipe and financed the bulk of the experimental work; to the Hammel Oil Burning Equipment Company, who paid for the installation of the 4 -in. pipe line and for some additional experimental work; and to the Parks-Cramer Company and The Texas Company, who supplied the oils used.

Apparatus

The installation for the experimental work is shown diagrammatically with essential dimensions in Fig. 2, and by photographs, Figs. 3 and 4 . It included a 35-h.p. motor driving a rotary gear pump connected on the suction side by 4 -in. pipe to a 10 -ft. by 5 -ft. diameter storage tank. The discharge of the pump was connected by convenient valves 


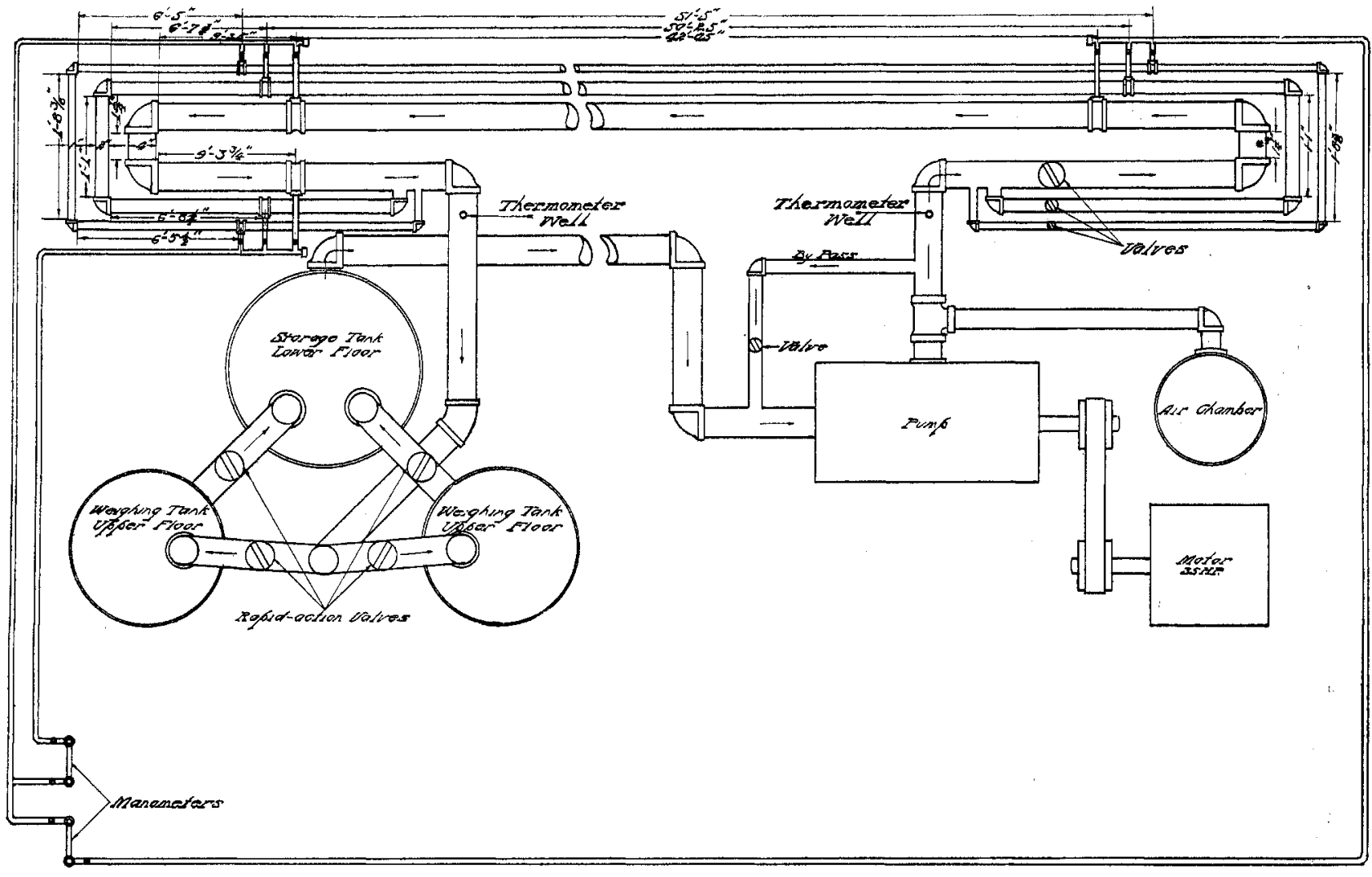

Fio. 2-Diagrammatsc Layout of Apparatus yor Pumping Viscous Lroutds

(Not drawn to scale)

to about $150 \mathrm{ft}$. each of 4-in., 2-in, and 1-in. "Welding Scale Free" standard steel pipe, made by the National Tube Company. The actual diameters were measured and found to correspond within the limits of error to the standard dimensions (Table II). These lines led to a common 4-in. riser equipped with quick-acting valves leading to two weighing tanks $5 \mathrm{ft}$. by $4 \mathrm{ft}$. in diameter. The weighing tanks were on the floor above storage tank, which conveniently allowed the liquid to flow back to the storage tank by gravity. The pressure drop was measured by means of a vertical glass U-tube about $10 \mathrm{ft}$. high containing water on mercury, which measured pressure differences up to $100 \mathrm{lbs}$. per sq. in. This manometer was connected by $3 / 8$-in. pipe lines to include either $42.04 \mathrm{ft}$. of 4 -in. straight pipe, $50.21 \mathrm{ft}$. of 2 -in. straight pipe, or $51.42 \mathrm{ft}$. of 1-in. straight pipe by valve manipulation. The straight pipe was continued about 10 $\mathrm{ft}$. on each side of manometer connections to eliminate all effect of the bends. The manometer pipe lines containing oil led to a 3-in. diameter chamber above the manometer half full of water, while the lines from this chamber to the mercury manometer were full of water. This scheme allowed instantaneous pressure readings, despite the high viscosity of the oils. The pressure drop in lbs. per sq. in. for this system can readily be shown to be $\frac{(13.6-1) \times 14.7}{13.6 \times 2.54 \times 30}$ or 0.179 times the manometer reading $(R)$ in $\mathrm{cm}$. A similar but smaller manometer measured the pressure drop around the bends, which in each case consisted of two standard $90^{\circ}$ elbows (in the three pipe sizes listed above) connected by a close nipple, with straight pipe leading to the manometer connections which were from $6 \mathrm{ft}$. to $10 \mathrm{ft}$. on each side of the bends. The storage tank was equipped with a steam coil for heating the liquids. Mercury thermometers were provided to indicate the temperatures of the oil at entrance and exit, while a by-pass around the pump afforded adequate control of the flow. A large air chamber beyond the pump served to damp out pressure fluctuations.

\section{ProcedURe}

A series of runs was made at a definite oil temperature varying from low to high rates of flow and vice versa. The whole system was first brought to a condition of steady flow, and then suddenly switched into the empty weighing tank, recording the time with a stop watch. The average duration of an individual run was from 1 to 4 min., during which time the discharge was accurately weighed, the pressure drops in the straight pipe and around the bend were noted, and the entrance and exit temperatures were read. A series of seven to ten runs at different velocities was made with each oil at each temperature. The total number runs made in the course of the experiments was about 400 .

As noted previously, the "pressure drop around the bend" included the drop due to two elbows and three connecting sections of straight pipe. In order to calculate the effect due to the elbows alone, a correction obviously had to be made.

The pressure drop through the straight pipe between manometer connections (excluding the two elbows) was calculated from the data secured at the same time on straight pipe alone, and this amount was subtracted from the total pressure drop around the bend as measured by the manometer. This value divided by two gave the pressure drop for one standard $90^{\circ}$ elbow.

Four different oils were used in the course of this investigation. They may be briefly described as follows:

1-Mexican petroleum, a crude asphalt base oil, one of the most viscous oils handled commercially, was used to obtain data in the upper viscous flow region.

"The words "upper" and "lower" in this paper refer to regions with comparatively high or comparatively low values of $f$ as indicated on Fig. 12 , etc, 
2-For the lower ${ }^{7}$ part of the viscous flow region, recourse was had to Meprolene, a refined paraffin base oil used in oil heating systems. This oil had a somewhat lower viscosity than

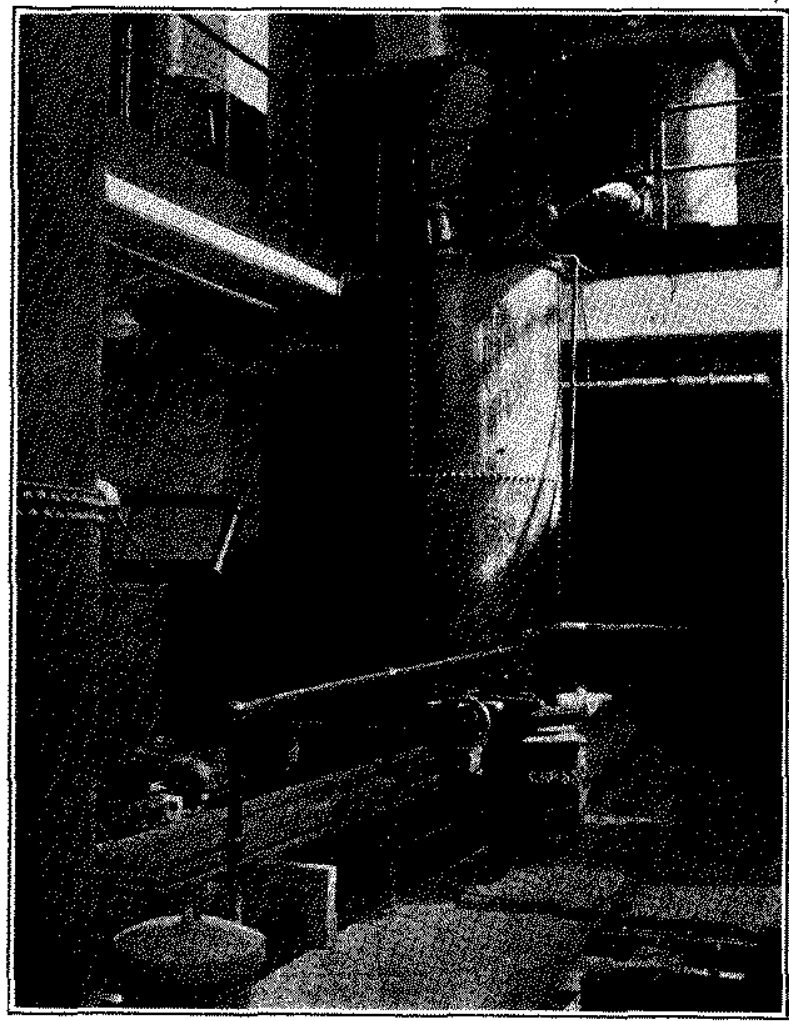

Fig 3-Showing Two Werghne Tanks (Amove), Storaga Tank, AND ONE END OF PIPE LINES

the Mexican petroleum and could be heated much hotter without changing in composition, so it was used over a wide range of viscosities.

3-Port Arthur light crude, a rather fluid fuel oil, was used to cover the upper portion of the turbulent flow region, in which few data were available.

4-Modified Port Arthur, made by adding one barrel of Mexican petroleurn to fourteen barrels of the above oil, was employed in order to get a series of points in, and on both sides of, the critical range.

Table I summarizes all essential information with regard to the four oils.

\begin{tabular}{|c|c|c|c|c|c|c|c|}
\hline \multirow{4}{*}{$\begin{array}{c}\text { Oxt. } \\
\text { Mexican } \\
\text { Petroleum }\end{array}$} & \multirow{4}{*}{$\begin{array}{l}\text { Source } \\
\text { Hammel Oil } \\
\text { Buming } \\
\text { Equip. Co. }\end{array}$} & \multicolumn{3}{|c|}{ TABLE I } & \multicolumn{2}{|c|}{ Vxscosiny } & \\
\hline & & \multicolumn{2}{|c|}{$\begin{array}{l}\text { GRAVITY } \\
\text { AT 70 }\end{array}$} & \multicolumn{2}{|c|}{ CENTIPOISES } & SaX & $\begin{array}{l}\text { BOLT } \\
\text { NDS }\end{array}$ \\
\hline & & SP. GR. & ${ }^{\circ} \mathrm{B} \hat{\mathrm{A}}$. & $70^{\circ} \mathrm{F}$. & $100^{\circ} \mathrm{F}$ & $70^{\circ} \mathrm{F}$. & $100^{\circ} \mathrm{F}$ \\
\hline & & 0,080 & 357 & 4370 & 970 & 20700 & 4700 \\
\hline Meprolene & Parks & & 10.8 & & & & \\
\hline & Cramer Co. & 0.900 & 25.4 & 3400 & 815 & 17100 & 4200 \\
\hline $\begin{array}{l}\text { Port Arthur. } \\
\text { Light Crude } \\
\text { Modified }\end{array}$ & $\begin{array}{l}\text { The Texas } \\
\text { Company } \\
\text { The Texas }\end{array}$ & 0.903 & 25.0 & 65.7 & 30.7 & 330 & 157 \\
\hline Port Arthur & Company & 0.910 & 23.8 & 86.0 & 39.6 & 430 & 202 \\
\hline
\end{tabular}

The viscosity-temperature curves for the four oils are shown on Fig. 5.

The results obtained from the 400 runs on the four oils, together with those in the literature on the flow of water, air and steam, and a little on oil, were sufficient to cover the whole range of conditions likely to be encountered in commercial practice.

\section{Discussion of Results}

METHOD OF PRESWNTATION-The reader who is interested solely in the practical use of the methods of calculation herein recommended may well refer at once to the later section describing only the recommended methods of calculation. However, in order to present the basis for and show the validity of these final conclusions, it is necessary to discuss in some detail the theory and existing data pertaining to the flow of fluids.

The engineer who is habitually making calculations for the flow of a given type of fluids through pipe lines is usually able to assemble from various sources some data or empirical equations applicable with fair accuracy to the particular set of conditions in which he is interested, and to develop a reasonably satisfactory procedure for making the necessary calculations. Even for the comparatively simple case of water, however, interpolations must be made from values given in tables for arbitrary friction factors, and the values given by two different references are likely to vary by as much as 30 or 40 per cent. Furthermore, no mention is made in most texts on hydraulies of the possibility of straight line flow for water, which does take place in small tubes at moderate velocities. The use of the customary formula in this range will cause enormous errors.

Much less fortunate, however, are the majority of chemists and engineers who have but infrequent oecasion to make such calculations, especially if they venture out of the beaten path of the flow of water, air, or steam. Fundamental exposition of the general laws of flow are rare, usually highly mathematical, and expressed in absolute units. Practical data, on the other hand, are scattered in many different periodicals, expressed in a wide variety of units, and generally cover only a narrow range of data on a given article. In the typical reference handbooks different empirical formulas are given for the flow of air, steam, and water, but even with the aid of all the foregoing information it is impossible for one unfamiliar with the subject to calculate the rate of flow of an oil, knowing merely the Saybolt seconds, or of a gas, knowing its viscosity. As a result of this situation, the average engineer has almost completely lost sight of the fact that all fuids obey identically the same fundamental laws of flow.

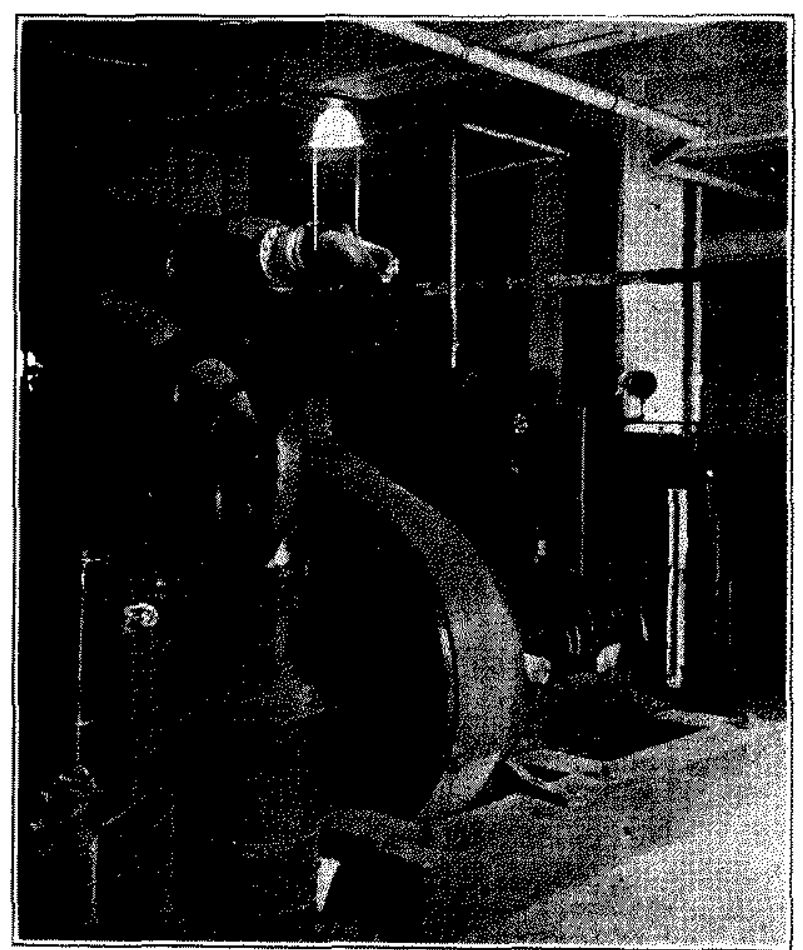

Fig. 4-Showne Pump ano Mamomethes 
Most of the foregoing difficulties are due simply to the failure to treat the whole subject of the flow of fluids in a comprehensive manner and in a place readily accessible to the average individual. There are, however, two more

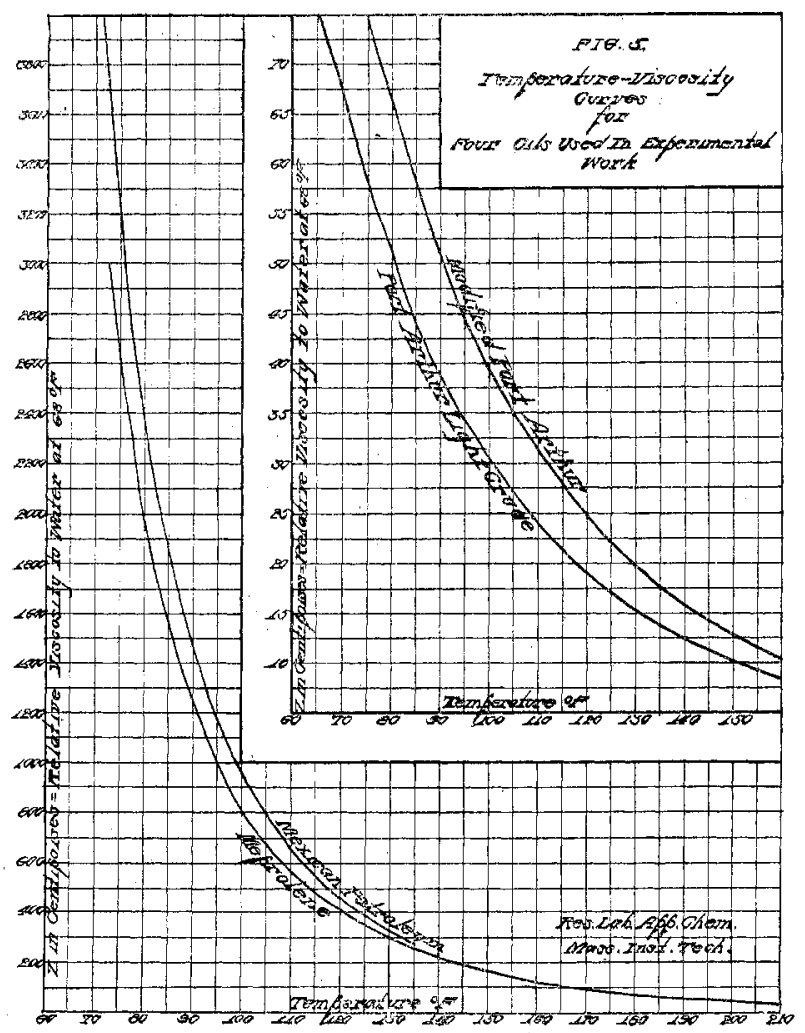

serious difficulties which are somewhat harder to solve satisfactorily: first, the fact that the two kinds of motion follow two different formulas, which greatly complicates the calculations required to be certain of the correct result; and second, the fact that in the formula for turbulent flow there is a variable coefficient $f$, which is a somewhat indefinite function of velocity, pipe diameter, viscosity, density, and condition of the pipe surface.

When dealing with water alone, where the density is substantially constant, and variations in viscosity are usually disregarded (though they should not be), it is of course possible to meet the situation fairly well by the use of tables showing the value of $f$ for different velocities and pipe sizes. When, however, an attempt is made to extend the formula to cover other liquids and gases, thus bringing in two additional variables, viscosity and density, which affect $f$, the situation apparently becomes well-nigh hopeless. As a result the common practice has been to work out separate formulas or flow tables holding over certain ranges for each of the common fluids, and to leave the rest of the subject to be covered by some very rough general formulas, frequently with fractional exponents applicałle only over a limited range.

Fortunately, however, it has been predicted, apparently first by Stokes $^{8}$ in England about seventy years ago, and since then rediscovered by several others ${ }^{9}$ interested in the theoretical side of the flow of fluids, that although the variable friction factor $f$ is a function of the four variables

8 Math. and Phys. Papers, Vol. III (1850), 17

- Reynolds, Trans. Roy. Soc. London, 1883, 935; Helnholtz, "Wissenschaftliche Abhandlungen," I (1873), 158; Rayleigh, Phil. Mag., 48 (1889), 321; Iamb, "Hydrodynamies of Fluids," Cambridge Univ. Press, 4 th Ed., 658 . above mentioned, it is not an independent function of these quantities, but a function only ofthe expression $\frac{D v s}{z} \cdot 10$

This obviously makes possible a great simplification in the treatment of the subject, but it has unfortunately been mentioned almost exclusively in highly mathematical papers dealing primarily with the theoretical side of the flow of fluids.

In 1912 Blausius ${ }^{11}$ gave a good review of the theory, recalculated the data of Saph and Schoder ${ }^{12}$ for water in smooth brass and galvanized iron pipes and the data of Nusset $t^{13}$ for compressed air, and showed that $f$ was a function of $\frac{\mathrm{D} v s}{z}$, as required by the theory. This paper has apparently been almost completely overlooked outside of Germany.

By far the most thorough existing treatment of the subject from this point of view is in connection with the recent work (during the war) of the British National Physical Laboratory, ${ }^{14}$ who used the method in the presentation of accurate data over a wide range. This work of the N. P. L., primarily on air and water, in very smooth tubes up to 3 in. in diameter, definitely substantiated for these conditions the prediction of Stokes and others that the friction factor $f$ is, within the limits of error, a function of the simple ratio $\frac{\mathrm{D} v s}{z}$ rather than an independent function of the separate variables. These important results have received surprisingly little attention in this country. ${ }^{15}$

While the method of treatment hereinafter followed is based primarily on this valuable work of the National Physical Laboratory, the following modifications or amplifications of that work have been made in this article:

1-For the sake of convenience in practical use, all results are expressed in English engineering units, rather than absolute or metric units.

2-Less emphasis is placed on the unstable region of flow between viscous and turbulent motion.

3-Extensive data have been obtained on commercially smooth pipes with standard couplings, which are shown to give different results from the extremely smooth drawn brass tubes used by the N.P. L.

4--Data have been secured, mainly from the literature, on much larger sizes of pipe than the comparatively small tubes tused by the N. P. L.

5-Many more data have been secured on the flow of highly viscous liquids through commercial pipes.

6-Complete details are given to make possible the use of a single method of calculation for all types of flow, which is highly desirable from a practical standpoint.

10 This is due to the fact that $f$ is a factor "without dimensions," and bence can only be a function of another expression without dimensions. The only combination of the four factors $D, 0, s$, and $z$ which cancels out all dimensions, is the expression $\frac{\mathrm{D} v s}{z}$. It is not necessarily independent of the units used, unless consistent absolute (either English or French) units are used for all quantities, which is not the case in this article.

i1 $Z$. Ver. deut. Ing., 56 (1912), 639

12 Trans, Am. Soc. Civil Eng., 51 (1903), 253.

13 "Mitteilungen aber Forschungsarbeiten," 44.

14 Collected Researches, National Physical Laboratory, Teddington, England, Stanton and Pannell, Vol. 11 (1914), and Pannell and Higgins Vol. 13 (1916). This is herealter called the "N. P. L." data and curves. 1 Since this paper in preliminary form was presented at the Chicago meeting of the American Chemical Society (September 1920) an article by A. C. Preston has appeared in Chemical and Metallurgical Engineering, for September 29 and October 6, 1920, which presents some of these results in graphic form. The Kinney Manufacturing Company and the KingKnight Company have also published two editions of an excellent booklet of the flow of oils which makes nse of these N. P. L. data and method of presentation. Buckingham also discusses these data mathematically in the Trans. A m. Soc. Mech. Eng., 37 (1915), 263. 
In making use of the fortunate fact that $f$ in Fanning's equation is a function of $\frac{\mathrm{D} v s}{z}$ rather than of all the variables independently, the obvious way to present experimental data is to plot the values of $f$, calculated from Fanning's equation for a given set of observations, against the corresponding value of $\frac{\mathrm{D} v s}{z}$.

At first sight this method of presentation would seem applicable only in the region of turbulent flow, since a different law, Poiseuille's (where $p=0.000668 \frac{l v z}{\mathrm{D}^{2}}$ ), is known to hold for the region of viscous flow. However, by comparing this equation with Fanning's $\left(p=0.323 \frac{f l s v^{2}}{\mathrm{D}}\right)$, it will be noted (as pointed out by Blausius) that if $f=$ $0.00207 \frac{z}{\mathrm{D} v s}$, the two equations become identical. Furthermore, values of $f$ which fulfil the latter equation must all lie on a line (straight on a logarithmic plot) on the abovementioned plot of $f$ against $\frac{\mathrm{D} v s}{z}$. It is therefore possible to calculate all experimental results, regardless of the type of flow, on the basis of Fanning's equation, and plot the resulting values of $f$, which should approximate the abovementioned line if Poiseuille's law holds for a given case. Conversely, by referring to such a diagram for the values of $f$ corresponding to a given value of $\frac{\mathrm{D} \eta s}{z}$, it becomes possible to calculate the pressure drop for any condition of flow using only a single formula (Fanning's).

This method of presenting data is therefore used throughout the following discussion. It may be well at this point for the reader to refer to Fig. 12, which shows the value of $f$ (plotted logarithmically) over substantially the entire range of conditions met with commercially. For convenience in the presentation of experimental results, this curve has been enlarged, divided into three sections, and the data pertaining to each one discussed separately.

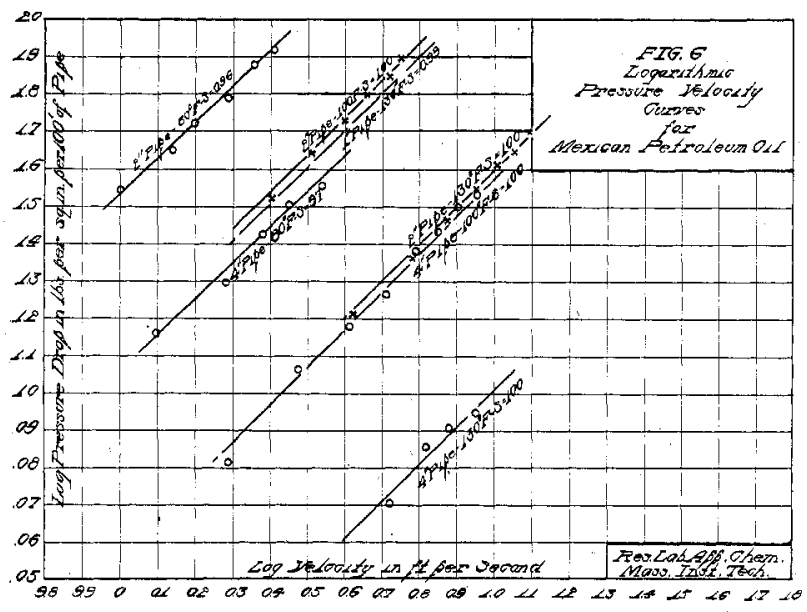

DATA IN VISCOUS FLOW REGION-Three sets of runs have been made by this Laboratory in the viscous flow regionone with Mexican crude in the highest viscosity region; one with Meprolene over a wide intermediate range of viscosities obtained by varying the temperature; and a few results with modified Port Arthur in the smaller sizes of pipe.

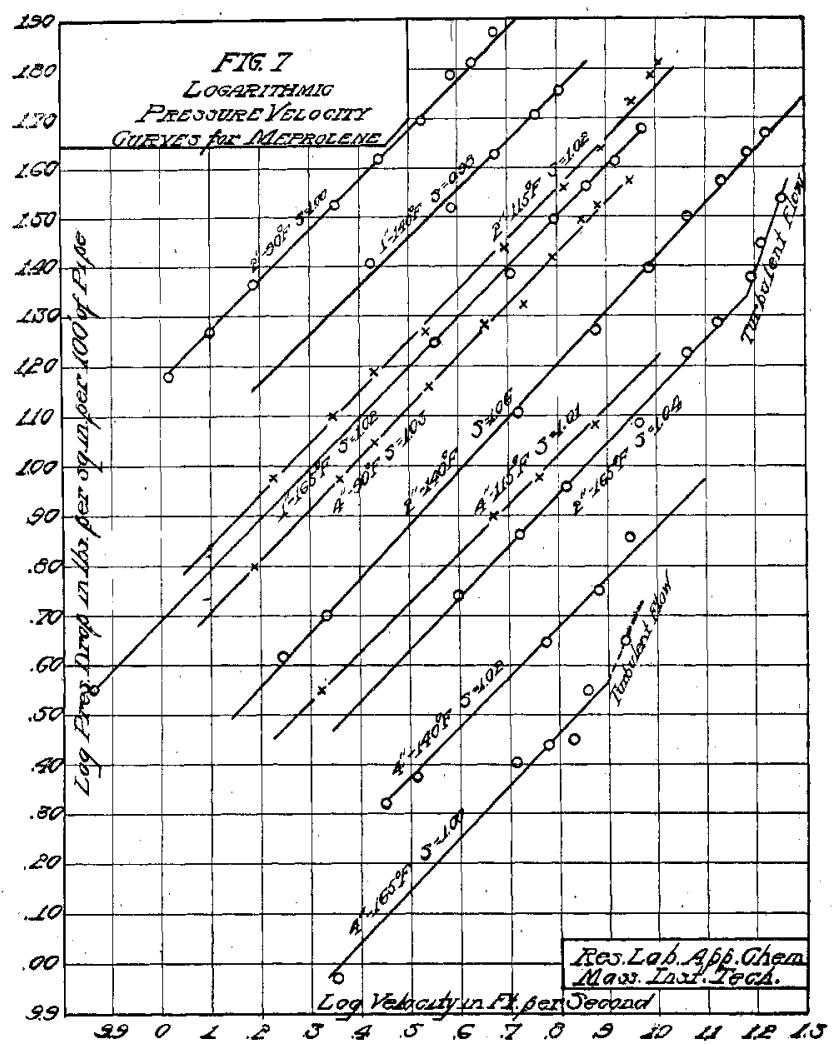

The individual observations on the first two oils are most definitely shown in Figs. 6 and 7, where the logarithm of the velocity is plotted against the logarithm of the pressure drop in each series of runs in which the viscosity and pipe size were kept constant. This is a convenient method of checking up on the variability of individual results and showing a large number of points in which all the data with regard to a given run are evident from an inspection of the plot (which is not true when the observed value of $f$ is merely plotted against $\frac{\mathrm{D} v s}{z}$, as in Fig. 8).

Through each of these series of points the best representative line has been drawn and the slope is indicated in the figures. According to Poiseuille's law the pressure drop should be proportional to the velocity and these slopes should equal 1.00. Actually they are found to vary from 0.95 to 1.06, with an average of 1.01. As far as the velocity-pressure drop relationships are concerned, therefore, Poiseuille's formula appears to hold within the limit of error of the experiments, which is rather high in case of the heated oils in viscous flow because of the nonuniform distribution of temperature throughout the pipe. It will be noted that the concordance of the individual points with the line is satisfactory in substantially all cases. Data on the Mexican petroleum in 1-in. lines are omitted because (on account of the high frictional resistance) the temperature of the oil rose as much as $10^{\circ}$ or $12^{\circ}$ in passing through the pipe and it was impossible to get reproducible or concordant results.

It will also be noted that two of the lines show breaks in the slope, indicating a change from viscous to turbulent flow in the cases of the 2 -in. and 4 -in. pipes with the hottest oil $\left(165^{\circ} \mathrm{F}.\right)$.

Since the number of individual observations in this range was so large, the method of checking up the results as a whole (as to the effect of viscosity and pipe size as well as velocity) by plotting the calculated values of $f$ was not applied to each individual observation, but to three points - 
one from the middle and one from either end of each of the lines shown in Figs. 6 and 7 . The points thus obtained are shown graphically in Fig. 8. It will be noted that in the upper portion of the plot they agree very well, but in the

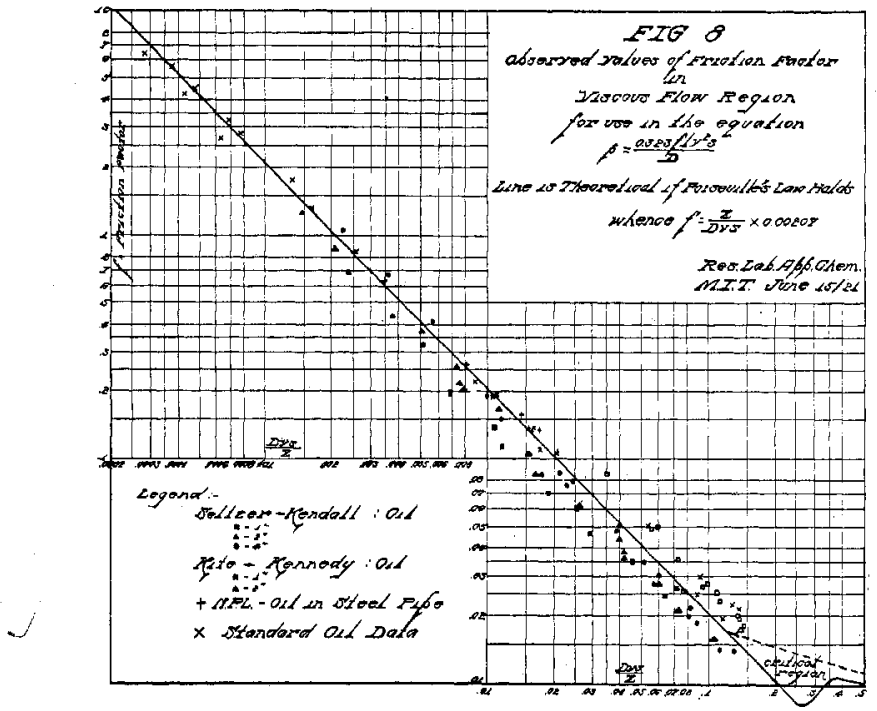

lower portion the majority of the points determined by Seltzer and Kendall fall below the theoretical line. This deviation is unquestionably due to the fact that all results lying in this region were obtained by the use of the Meprolene heated to a fairly high temperature. In such cases there is a very wide temperature gradient between the warm center and the cold outside of the pipe, due to the absence of any convection or mixing currents in viscous flow, and it is practically impossible to make an accurate measurement or calculation of the effective average temperature. The temperatures used in the calculations were measured by thermometers in wells in the 4-in. pipe line just beyond the entrance and exit of the 2-in. and 1-in. lines, as indicated in Fig. 2. The thermometer therefore recorded a temperature nearer to that of the pipe and the outside cool layers of the oil than to the true average effective temperature, since most of the flow was undoubtedly taking' place in the hot center core. The theoretical values of the friction factor corresponding to these high values for the viscosity were, therefore, higher than the observed points in the region where measurements were made on hot oil. The deviation averaged about 17 per cent in the highest temperature runs, and was worst, as might be expected, in the 1-in. pipe, where the velocity through the 4-in. exit line was extremely low. An error of only $3^{\circ}$ or $4^{\circ}$ in the effective average temperature would account for the above divergence.

In order to obtain some further data another brief series of runs was made by Kite and Kennedy covering the lower portion of this region, using the modified Port Arthur oil at ordinary temperatures. For some unexplained reason (possibly an error in the viscosity determinations) the results of this series of runs (hollow squares on Fig. 8) were about as much above the theoretical line as the other series were below, the average of the two checking the theoretical line very closely.

The only other satisfactory data on viscous flow of heavy oils through commercial pipes appear to be the single set of experiments of the N. P.L., and some results of the Standard Oil Company of California on pipes up to 12-in. diameter, published in their bulletin on the California Oil Pipe Line. Representative points from both of these sources are also recorded on Fig. 8. In calculating over the latter results use was made of a table of viscosities, privately com- municated by the Standard Oil Company, correcting the data given in the booklet.

Considering the results as a whole, while there is considerable variation both above and below the line, due to factors such as frictional heating in the pipe and variations in temperature between the inside and the outside, there can be no real doubt as to the essential validity of Poiseuille's formula for viscous flow in pipes of commercial size and roughness. Since the same law has been checked up very closely for all types of liquids in extremely smooth glass and metal tubes, it is evident that the roughness of the pipe is a comparatively small factor in determining the resistance to viscous flow-as might indeed be anticipated on theoretical grounds, since there is in any case a practically stationary and fairly thick film of oil on the inside surface of the pipe. It will be noted that this conclusion is quite different from that drawn from results obtained in the turbulent flow region.

DATA IN CRITICAL AND LPPER TURBULENT FLOW REGIONSPossibly the most interesting, and at the same time the most troublesome, portion of the subject of the flow of fluids is the critical region between viscous and turbulent flow. Fig. $8 a$ brings out the essential facts as they appear from a careful study of the various experiments (usually in small tubes) described in the literature. ${ }^{16}$ The solid lines are the portions of the viscous and turbulent flow curves about which there is little doubt; the turbulent flow line extended to the left intersects the viscous flow line at Point 1 frequently referred to as the "minimum" critical point. The weight of evidence seems to indicate that these two intersecting lines represent the most stable conditions of flow, it being noteworthy that the type of motion giving the largest value of $f$ (and hence the greatest dissipation of energy) for a given value of $\frac{\mathrm{D} v s}{z}$ is the one which tends to prevail.

Actually, however, it is observed in careful laboratory experimentation that viscous flow has a marked tendency to perpetuate itself under conditions where turbulent flow would be expected, while the opposite tendency has never been noted. If, for a given liquid flowing through a given pipe, the velocity (and hence $\frac{\mathrm{D} v s}{z}$ ) is gradually increased and no disturbing influences are present, the observed values of $f$ tend to follow the dotted extension of the viscous flow line for some distance beyond the lower critical point, and observations to determine the type of flow by means of colored threads of liquid indicate that it is still viscous. Sooner or later, however, a point is reached where the flow suddenly changes to turbulent and the values of $f$ quickly rise to the turbulent flow line, as indicated on Fig. 8a. There is wide disagreement as to the exact location of this "higher" critical point, ${ }^{17}$ the evidence indicating that, as would be expected for an essentially unstable type of flow, it varies greatly with conditions; many disturbing factors, such as surface roughness in the pipe, the presence of valves and fittings, changes in cross-sectional area, vibrations, turbulence of the entering water, all tend to make the change from viscous to turbulent flow come sooner than under more ideal conditions.

Properly speaking, therefore, reference should be made to a critical region, rather than to a critical point or points. Furthermore, most authorities state that if this critical region is entered by gradually lowering the velocity from the

16 Lamb, "Hydrodynamics," 4th Ed. (1916), Cambridge Univ. Press, 651; Russell, "Textbook of Hydraulics" (1908), 110; Reynolds and Osborne, Proc. Roy. Soc. London, 35 (1883), 94; Barnes and Coker, Ibid., 74 (1904-5), 341

17 There is also some disagreement in the literature as to whether Point 2 or 3 should be called the higher critical point. 
turbulent flow side, the tendency is to follow the dotted turbulent flow line clear over to the point of intersection, without any abnormal dip in the observed values of $f$. Experimental results seem to indicate, however, that while turbulent

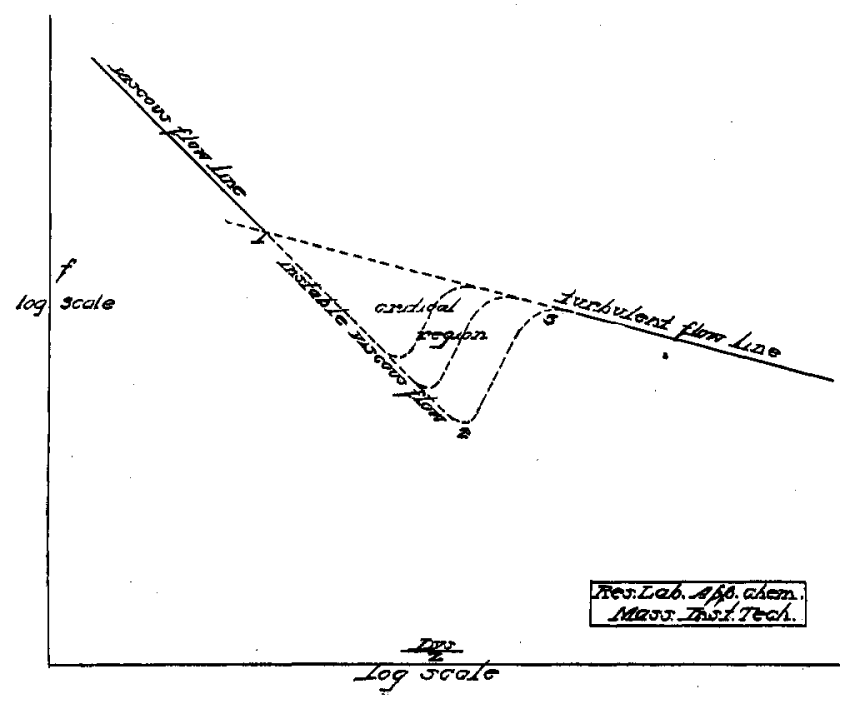

Fig. 8a-Diagrammatic REPRESENTATION OF DIFFERENT Flow Curves Obtained in the Critical FLow RzGION

flow tends to persist longer under these conditions, it may nevertheless return to viscous flow before Point 1 is reached.

The N. P. L., working with extremely smooth tubes, have obtained the most consistent series of data in this region which has thus far been available, practically all their points falling within 3 or 4 per cent of the curve shown in Fig. 9. (The number of points determined by the N.P. L. is so large that reference must be made to the original article for such details.) The recalculated data of Saph and Schoder $^{12}$ also check this eurve very well, showing that, with very smooth pipe, even the critical region gives fairly consistent values of $f$ when plotted against $\frac{\mathrm{D} v s}{z}$. The abnormal dip in the curve as determined by them is both wider and deeper than would be indicated by a few experiments under commercial conditions, though it is less pronounced than has been found by some experimenters under ideal conditions in glass tubes.

In view of the almost complete lack of accurate data for commercial pipes in this region, this Iaboratory undertook a rather extensive investigation of the phenomenon in 1-in., 2-in., and 4-in. pipes, with the Port Arthur light crude and modified Port Arthur oils, the results of which are shown in Fig. 9. Since the observed points indicate a much smaller dip in the critical region for commercial pipe than is found by the N. P. L. (undoubtedly due to surface roughness, the presence of couplings, vibrations, etc.) and furthermore, since the presence of other disturbing factors or special operating conditions are at any time likely to bring the pressure drop up to the theoretical line for turbulent flow, it appears to the authors that the proper treatment of this region for practical purposes in commercial pipe lines is to assume the turbulent flow line as extending straight over to the viscous flow line, thus simplifying the treatment and being on the safe side in all calculations. This would, of course, lead to slight errors if the pressure drop through a commercial pipe line were used as a measuring system in this region of flow, but no such method of measurement, regardless of the friction factors assumed, can give reliable and reproducible results in this unstable region.
This method of treatment indicates that the critical velocity for commercial pipes occurs when $\frac{\mathrm{D} v s}{z}=0.12$ or $v=\frac{0.12 z}{\mathrm{D} s}$, which is much lower than the values based on work in glass tubes, which are the ones customarily quoted in reference books. As indicated above, however, the flow is variable and uncertain for values of $\frac{\mathrm{D} v \mathrm{~s}}{z}$ between 0.12 and 0.4 (or possibly even higher under ideal conditions) and reference should be made to a critical region rather than to a critical point or points. Fortunately, in the method of calculation recommended hereinafter there is no need whatever of knowing the critical velocity, since the same formula is used for both types of flow.

Considering next the upper part of the turbulent flow region, also shown in Fig. 9, the data obtained in this Laboratory by Kite and Kennedy, and by Lewis, ${ }^{18}$ appear to be the only reliable data for commercial pipes in this region, although there are a considerable number available in the lower part of the turbulent flow region. It will be noted that the concordance of the points (except a few of Lewis') is much better than it was in the viscous flow region, owing to the fact that in turbulent flow the temperature is substantially constant throughout the pipe, and that variations in viscosity have much less effect in turbulent than in viscous flow. Furthermore, there is no consistent difference between 2 -in. and 4 -in. pipes, though the 1 -in. results appear to average very slightly higher. The results are, however, consistently higher than those obtained by the N. P. L. on smooth pipe in the same region-the divergence averaging about 15 per cent. Unfortunately, practically no other data are available to serve as a check upon these results, but as will be noted later from a consideration of Fig. 10, the results are entirely consistent with those obtained by many observers in the lower part of the region.

DATA IN LOWER TURBULENT FLOW REGION-This Laboratory has secured no original data in the lower turbulent flow region, primarily because this appeared to be well covered by the results of a number of other experimenters both in very smooth and in commercial pipe.

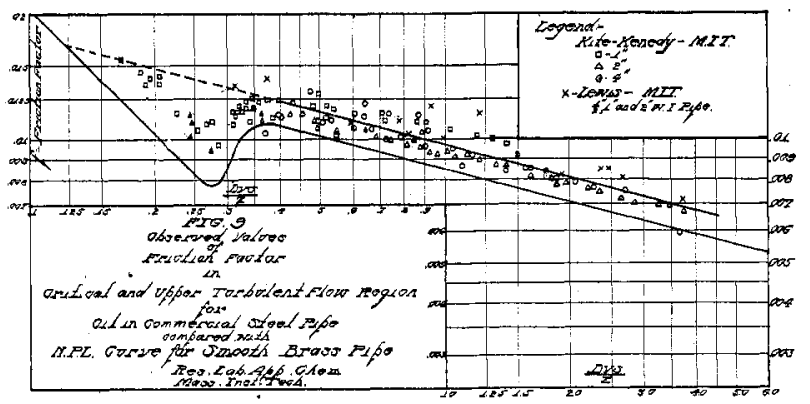

Again, for very smooth pipe, the lower line in Fig. 10 represents very well the accurate and highly satisfactory data of the N.P. L., which are substantially identical with the curve obtained on recalculating the results of Saph and Schoder in smooth brass pipe.

There are certain other experimenters whose data appear to be thoroughly reliable and can be satisfactorily represented by a smooth curve in plotting $f$ against $\frac{\mathrm{D} v s}{z}$. It should be understood that most of these data were not presented in this form by the original authors, but have been recalculated

18 ThIs Journat, 8 (1916), 627. 


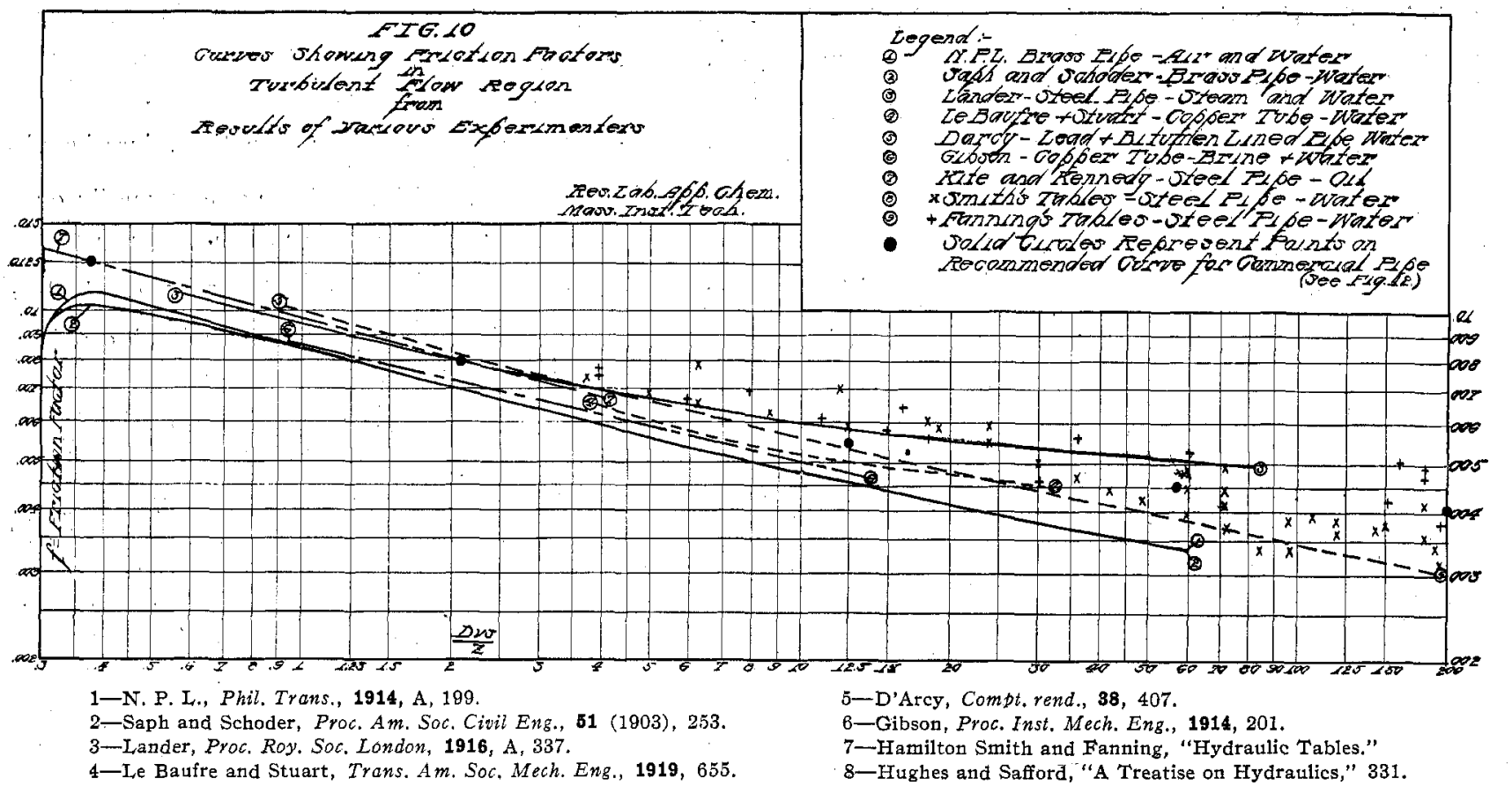

either by the N. P. L. or by this Iaboratory to put it in this more convenient form. Curves are in no cases drawn unless there is a reasonably good concordance among the points when thus calculated and plotted.

Considering briefly the other lines on Fig. 10, the results of Gibson with brine solutions in smooth copper tubing are also only slightly above the N.P. I. curve. The work of Le Baufre and Stuart on condenser tubes of Admiralty metal is still slightly higher than these results.

Undoubtedly, the best results on commercial steel pipes are the comparatively recent and extensive results of Lander, in England, who used steam and water flowing through steel pipe and obtained a very concordant series of results when plotted against $\frac{\mathrm{D} v s}{z}$. It will be noted that the upper part of Lander's curve checks very closely with that derived in this Laboratory for oil, while the lower part is still further above the curves for smooth pipe.

It would logically be expected that the tables given in reference books on hydraulics for the values of $f$ as a function of pipe diameter and viscosity would be the most satisfactory for the purpose of determining the proper curve to represent the extensive results on water in commercial pipes. The tables compiled by Fanning and those by Hamilton Smith are those most generally recognized and copied for this purpose. ${ }^{19}$

It was soon found, however, that plotting the values given by these authors against $\frac{\mathrm{D} v s}{z}$ gave widely scattering points, as is shown in Fig. 0 . Furthermore, deviations between the values given by the two authors were sometimes as great as 30 per cent (mostly in large pipes). A careful consideration of the results indicated further that, if these tables are correct, $f$ is not a function of $\frac{D v s}{z}$ for very large pipes such as are used in water mains.

Being somewhat reluctant, however, to accept this conclusion, the authors made an effort to resurvey the original data on which Fanning and Hamilton Smith based their

"For both sets of tables see Hughes and Safford, "A Treatise on Hydraulics," p. 331. tables. This inspection readily showed the difficulties encountered in attempting to work out these tables for very large pipes. In practically every case the data obtained by a given experimenter covered only one size of pipe, and, furthermore, no attempt was made to measure the temperature of the water. Since the viscosity of water varies about 25 per cent for a variation of $20^{\circ} \mathrm{F}$. it is undoubtedly an important cause of the discordant results reported. Other variations were undoubtedly caused, even in comparatively new pipes, by wide variations in roughness due to tuberculations, etc., on the surface of the pipes. Being compelled to derive formulas from this kind of scattered and unreliable data, especially for the larger pipes, it is obvious that considerable errors might be made in interpolating and extrapolating results to cover the whole field.

The authors therefore reached the. conclusion that the tables derived by Fanning and by Hamilton Smith were as good as could be worked out, considering the type of data which was available to them, but that the wide scattering of the values of $f$ when plotted against $\frac{\mathrm{D} v s}{z}$ does not in any sense prove that $f$ is not a function of $\frac{\mathrm{D} v s}{z}$. Typical individual points from the tables of these two authors are shown in Fig. 10. While the deviations are obviously large, their average deviation from the recommended curve for $f$ is no greater than that between the two tables themselves in the cases of the larger pipes. The results also indicate clearly that for commercial pipes, especially for high values of $\frac{\mathrm{D} v s}{z}$, the values of $f$ are very much higher than those obtained by the N. P. I. in smooth pipe.

It should be pointed out that for a given value of $\frac{D v s}{z}$ both tables tend to give higher f's for pipes of smaller diameter working at correspondingly higher velocities. This might appear to indicate that for very large pipes the effect of a given degree of surface roughness became relatively less, and that all large pipes gave results similar to the N.P. I. for very smooth pipe; on the other hand, it might merely be due to the fact that the large pipes were usually bitumen- 
covered wood and hence somewhat smoother than ordinary cast iron or steel. These results cannot, however, be given as much weight as those of Lander, which were obtained under much more carefully controlled conditions, although not in such very large sizes of pipe.

From a careful consideration of these results, this Laboratory has determined (see Fig. 12) what it believes to be the best values of $f$ for clean commercial pipes, at least those from 1 in. to $8 \mathrm{in}$. in diameter, in the light of all experimental data at present available. For larger pipes the best value of $f$ probably deviates toward the lower curve for very smooth pipes. For very rough or tuberculated pipes the friction factors may, of course, be much higher than the values given for commercially smooth steel or cast-iron pipes. The recommended line is not drawn in Fig. 10 because it would tend to obscure the other lines, but the solid circle indicates its location as drawn in Fig. 12.

This completes the consideration of the data on the flow of all fluids in both smooth and commercial pipe lines. The recommended friction factors for use under all conditions are shown in Fig. 12, as above noted. The mathematical significance of these lines, and the recommended methods of calculation, are discussed in later sections.

RESISTANCE TO FLOW THROUGH ELBOWS-The subject of the flow through elhows is another on which the data are very incomplete. The most convenient method of expressing the frictional resistance due to an elbow of given size is in terms of the equivalent length of straight pipe which will give the same resistance to the flow of a given liquid. The published results on this subject have indicated that the equivalent length of pipe in feet was nearly independent of velocity, but was almost directly proportional to the size of the elbow, and it has therefore become customary to express this equivalent length in terms of pipe diameters, rather than feet, so that the figure will be substantially the same for all sizes of pipe.

Expressed on this basis, the customary recommendation of handbooks is to allow from 30 to 50 pipe diameters for each elbow in a line. An inspection of the data indicates that this rule is fairly well justified for the case of water (though the figure of 50 pipe diameters is well on the safe side of most of the results). There are, however, comparatively few data in the upper part of the turbulent flow region, and apparently none whatever in the critical or viscous flow regions.

Fig. 11 presents in graphic form the results of the experimental runs in this Laboratory, in which the equivalent length of straight pipe in pipe diameters is plotted against $\frac{\mathrm{D} v s}{z}$. For reasons discussed in the next section, the resistance of the equivalent length of straight pipe was calculated from the recommended average line on Fig. 12, and not from the observed value in the simultaneous reading on the straight pipe in a particular experiment. A considerable proportion of the observed data had to be omitted from Fig. 11 to prevent the points from becoming crowded, but the points as given are strictly representative of all the results. In the lower turbulent flow region data are also added from other investigators which are quite consistent with the points determined by this Laboratory.

Of the points determined in this Laboratory, the results by Kite and Kennedy in 4-in. pipes at fairly high velocities appear to be distinctly lower than the results for 1-in. and 2-in. pipes, which agree very well. This effect is almost certainly due to the fact that the distance between the two elbows of the 4-in. line (see Fig. 2) was too small to permit the full disturbing influence of the first elbow to manifest itself, and the average pressure drop per elbow was therefore low, especially at high velocities, compared with that in 1-in. and 2-in. lines where the distance between the two elbows was comparatively large. This would also indicate that the resistance of a standard return bend would be distinctly less than that of two elbows placed some distance apart.

From a careful consideration of these results it appears to be fairly conclusive that the elbow correction, like $f$, is a

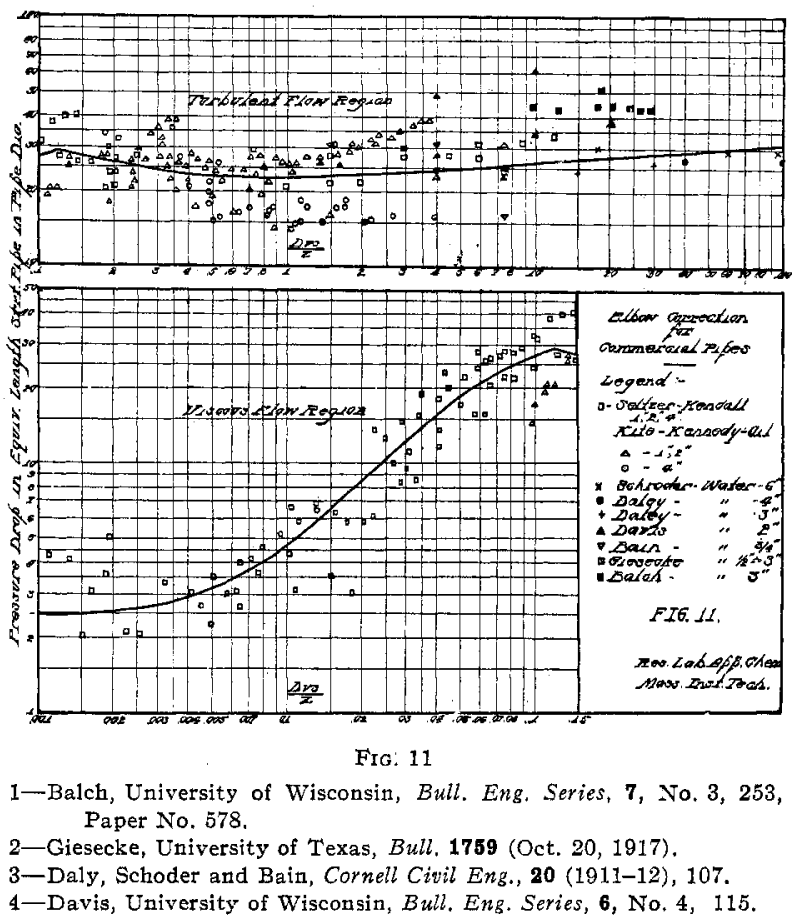

function primarily of the modulus $\frac{\mathrm{D} v s}{z}$. The rule of 30 pipe diameters per elbow appears to be about as good as can be derived for the entire region of turbulent flow. (The data, while apparently indicating the slight curvature as drawn, do not really justify anything more than a straight horizontal line.) However, Fig. 12 brings to light a hitherto unsuspected fact-namely, the existence of a sharp break in the correction curve at the critical velocity for commercial pipes beyond which, as $\frac{\mathrm{D} v s}{z}$ decreases into the region of viscous flow, the magnitude of the correction rapidly grows less, apparently flattening off for very small values of $\frac{\mathrm{D} v s}{z}$ to about 2 or 2.5 pipe diameters, which is little more than the actual length of the elbow itself. ${ }^{20}$

\section{Theoretical Aspects of the Results}

In the course of evolving the method of presentation given in the previous sections and recommended for practical use in the following section, a number of interesting points of theoretical importance have come to light and seem to justify at least passing comment. In most cases they amount to alternative methods of presentation of the same results, which need not concern one interested merely in the practical aspects of the problem.

The preceding results show clearly that for a very wide range of conditions $f$ is a function of $\frac{D v s}{z}$. What function?

20 The complete tabulated data on the 400 odd runs are obviously too bulky for reproduction, but are available for inspection at any time in the files of this Laboratory. 


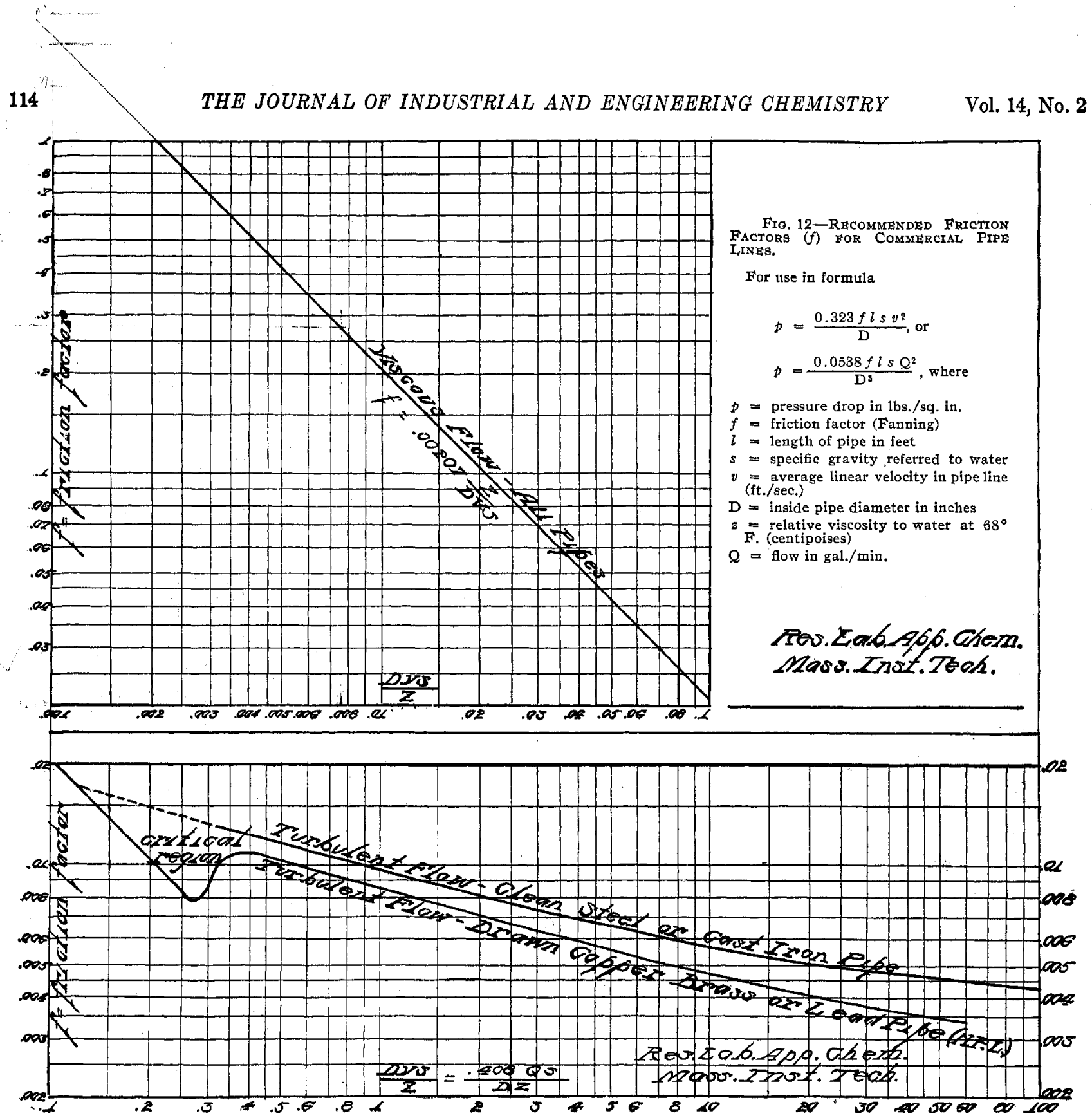

This important point and its significance have scarcely been mentioned.

Referring to Fig. 12, since the line for the viscous flow region is straight and at an angle of $45^{\circ}$ (slope $=-1$ ) it can readily be shown that its equation is

$$
f=0.00207 \quad \frac{z}{\bar{D} v s} \text {. }
$$

Substituting this value of $f$ in Fanning's equation, it is possible to derive a general equation for flow for this region which is, as noted previously, simply the modifed Poiseuille's equation,

$$
p=\frac{0.000668 z l v}{D^{2}}
$$

Deriving an equation for the curved line in the turbulent flow region is not, however, such a simple matter. The best form for the equation appears to be

$$
f=a+b\left(\frac{\mathrm{D} v s}{z}\right)^{n}
$$

where $n$ is a negative exponent. Using this form of equation and deriving the constants, it is found that the best equation

for urbulent flow in smooth pipes (as already worked out by Lees ${ }^{21}$ ) is:

$$
f=0.0018+0.00662\left(\frac{z}{\mathrm{D} v s}\right)^{0.355}
$$

Applying the same method to the recommended line for commercial pipe gives the new equation of the form:

$$
f=0.0035+0.00594\left(\frac{z}{\bar{D} v s}\right)^{0.424}
$$

Substituting the latter value of $f$ in the Fanning equation gives as the most accurate general equation for turbulent flow in commercial pipes the following:

$$
p=\frac{0.323 l s v^{2}}{\mathrm{D}}\left[0.0035+0.00594\left(\frac{z}{\mathrm{D} v s}\right)^{0.424}\right]
$$

A similar equation can readily be derived for turbulent flow in smooth pipes. It is obvious, however, that this equation is too complicated for any practical calculations-or indeed for giving a clear picture as to the comparative effects of the different variables. In order to secure such a semiquantitative visualization for the case of commercial pipes, it is

${ }^{21}$ Proc. Roy. Soc. London, 1914, 406. 
possible to draw a straight line which is fairly representative of the turbulent flow curve for commercial pipes in Fig. 12, which has the equation:

$$
f=0.01\left(\frac{\mathrm{D} v s}{z}\right)^{0.2}
$$

Substituting this value for $f$ in the Fanning equation, we obtain

$$
p=\frac{0.00323 s^{0.8} z^{0.2} l v^{1.8}}{\mathrm{D}^{1.2}}
$$

which is a reasonably accurate formula for the middle range of turbulent flow in commercial pipes. Actually, of course, the slope and the intercept of the curved line are continually changing, which changes the value of the constant in the above equation for $f$ from 0.01 to 0.007 , while the exponent varies from 0.13 to 0.26 . This accounts for the fact that many investigators studying a comparatively narrow range of data have proposed formulas with fractional exponents similar to that given above, but each writer gives different values for the constant and for the exponent, depending on the particular part of the region and condition of pipe surface with which they were working. When working with water alone, as in most of the experiments, $z$ and $s$ have both been erroneously assumed to be constant and therefore became part of the proportionality constant.

There are also certain matters of interest in connection with the flow through elbows. As noted in that section, the resistance through an elbow was figured in terms of the equivalent resistance of straight pipe as calculated from the straight line in Fig. 12, rather than in terms of the resistance of a straight pipe as measured in the same run. This made little difference, except in the critical region, but when the equivalent length of pipe was figured in terms of the abnormally low resistances actually measured in this critical region, the points in this vicinity formed a sharp hump for values of $\frac{\mathrm{D} v s}{z}$ between 0.12 and 0.35 , as compared with the smooth curve obtained when using the theoretical line as a basis. The latter method of presentation was not used merely on account of this fact, however, but because if the recommended line is used in making the calculations for the straight pipe, the elbow effect should also be figured in terms of that line. Furthermore, although in straight pipe there is unquestionably a tendency toward perpetuating viscous flow into the turbulent flow region, this unstable tendency is undoubtedly less pronounced during flow through an elbow and the pipe immediately beyond it, which will very probably force the liquid into turbulent motion. The method of presenting the results is therefore sound on theoretical grounds and confirms the belief that elbows tend to diminish the importance of the dip in the critical flow region.

\section{Recommended Methods of Calculation}

GENERAL PROCEDURE FOR CALCULATING PRESSURE DROP IN ANY PIPE LINE-With the data and charts previously presented, the calculation of the pressure drop through a pipe line under any specified set of conditions is a very simple matter. The steps involved may be outlined as follows:

$$
1 \text {-Calculate the value of } \frac{\mathrm{D} v s}{z} \text { (or its equivalent, } \frac{0.408 \mathrm{Q} s}{\mathrm{D} z} \text {, }
$$

if $Q$ is known rather than $v$ ) for the fluid and pipe in question. If there is any uncertainty as to the measurement or estimation of any of the quantities, see the subsequent section on determination of the known quantities.

2-By referring to Fig. 12 find the value of $f$ which corresponds to this value of $\frac{\mathrm{D} v s}{z}$, using the curve corresponding to the degree of roughness of the pipe in question. (See previous discussion of Fig. 12.) For values of $\frac{D v s}{z}$ less than 0.002 , extrapolations on the straight $45^{\circ}$ line for viscous flow may readily be made by dividing the abscissae by 10 (or 100) and simultaneously multiplying the ordinates by 10 (or 100).

3 -Using the same value of $\frac{D v s}{z}$, refer to Fig. 11 for the equivalent length of straight pipe corresponding to each $90^{\circ}$ elbow. Multiply this by the number of elbows, convert the correction from pipe diameters into feet, and add it to the length of straight pipe. (Note that two elbows very close together, or a return bend, have less effect than two elbows some distance apart.)

4-Insert this value of $f$ in the modified Fanning equation, $p=\frac{0.323 f l s v^{2}}{\mathrm{D}}$ or its equivalent, $p=\frac{0.0538 f l s Q^{2}}{\mathrm{D} E}$, and obtain the pressure drop directly. This method and this formula should be used regardless of whether the liquid is in viscous or turbulent motion.

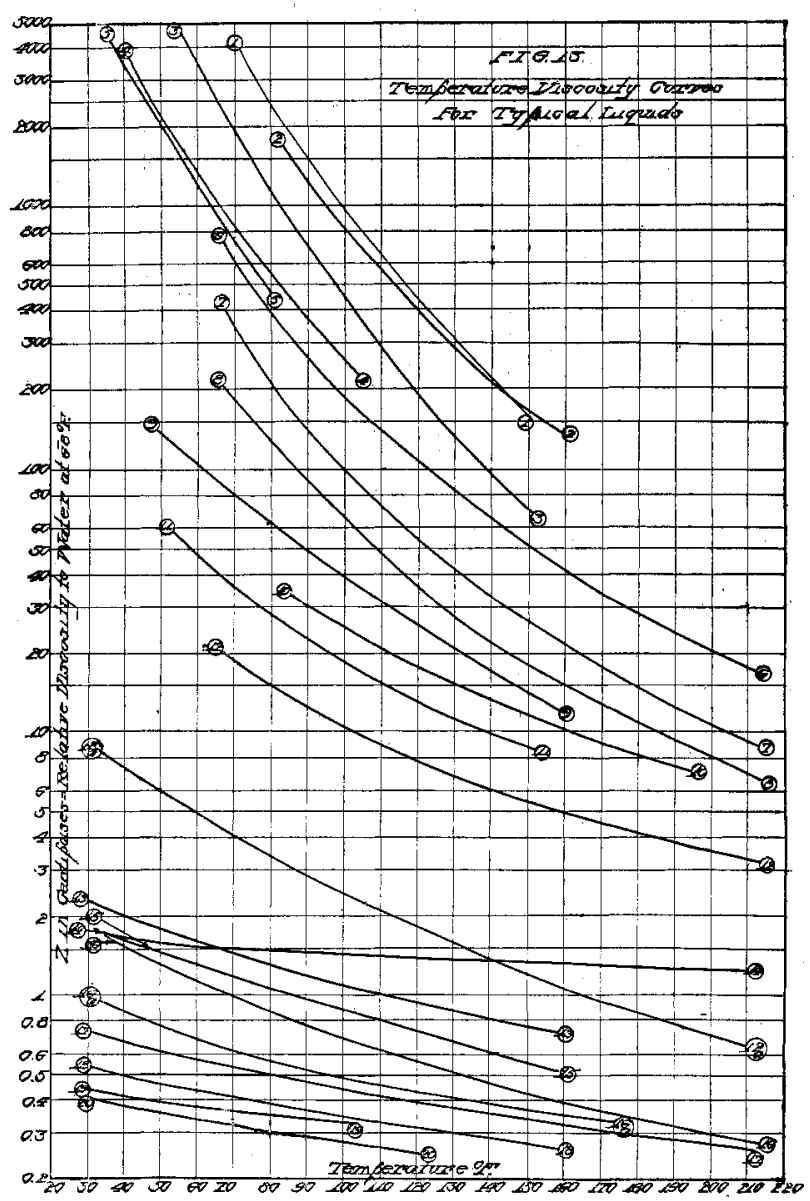

1-Mexican petroleum (Mex. Pet. Co.) (See Fig. 5)

2-Meprolene (Parks-Cramer Co.) (See Fig. 5)

3-Cal. heavy crude, $15.2^{\circ} \mathrm{Be}$. (Std Oil Co.)

4-Castor oil (Smithsonian Tables)

5-Glycerol (Smithon

-Glycerol (Smithsonian Tables)

6-Mobiloil B (Vacuum Oil Co.)

8-Texas engine oil (Vacuum Oil Co.)

8-Texas engine oil (Vacuum Oil Co.)
9-Olive oil (Smithsonian Tables)

9-Olive oil (Smithsonian Tables)
10-Linseed oil (Smithsonian Tables)

11-Cal. light crude $24.4^{\circ}$ Bé. (Std. Oil Co.)

12-Nonviscous neutral (Vacutum Oil Co.)

12A-Amyi alcohol (Opt. inactive) (Smithsonian Tables)

13-Mercury (Smithsonian Tables)

14-Turpentine (Smithsonian Tables)

15-Ethyl alcohol (Smithsonian Tables)

16-Water (Smithsonian Tables)

16A-Benzene (Smithsonian Tables)

16A-Benzene (Smithsonian Tables)

18-Octane (Smithsonian Tables)

19-Carbon disulfide (Smithsonian Tables)

20-Hexane (Smithsonian Tables) 
GENERAL PROCEDURE FOR CALCULATING OTHER QUANIITIES-The foregoing procedure must, of course, be slightly modified in case the permissible or available pressure drop is known and it is desired to calculate any one of the other

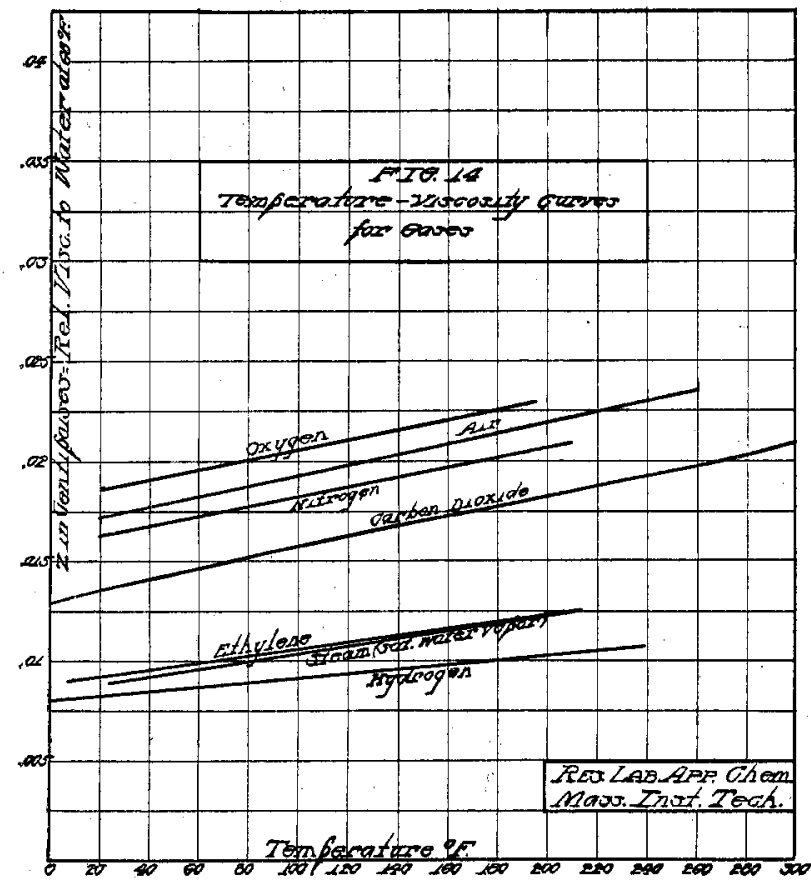

five quantities which may be unknown in a given practical problem. To anyone familiar with such calculations these modified methods are fairly obvious, but it will be helpful to those less familiar to suggest what appears to be the shortest way of arriving at the final results for each of the other cases.

1-If $l$ is the unknown (which seldom happens) calculate exactly as described in the previous section, but transpose the Fanning equation so as to solve for $l$ instead of $p$.

2 -If $z$ is the unknown (as when it is desired to know how hot an oil must be heated in order to give a specified discharge under definite conditions) calculate the permissible $f$ from Fanning's equation (which does not involve the assumption of any value for $z$ ): Then find the value of $\frac{D v s}{z}$ in Fig, 12 which corresponds to this value of $f$, and solve this latter equality for $z$, which is the only unknown involved (neglecting small variations in $s$ ).

3-If $\mathrm{D}, v$, or $s$ is the unknown (the latter only in handling gases) the situation is somewhat more complicated, since these quantities appear both in the friction modulus $\frac{\mathrm{D} v s}{z}$ and in Fanning's formula.

These cases may be treated by the customary method of trial and error used by hydraulic engineers, starting with a reasonable value for $f$, but experience with classes in chemical engineering indicates that for various reasons it is usually preferable to assume a value for the unknown and calculate the resulting pressure drop in the ordinary way. If this comes too high or too low, assume a new value for $\mathrm{D}, v$, or $s$ which will give more nearly the proper pressure drop. By remembering that, for a given $Q, p$ varies inversely as the fourth or fifth power of the diameter, the correct solution can very quickly be obtained. If the first approximation indicates that the value is in the viscous flow region, the simplest way to solve for one of these three variables is to substitute, the known quantities directly in Poiseuille's equation,

$$
p=\frac{0.000668 \approx l v}{\mathrm{D}^{2}}
$$

or its equivalent,

$$
p=\frac{0.000273 \approx l Q}{\mathrm{D}^{4}} \text {. }
$$

METHODS OF DETERMINING THE KNOWN FACTORS-Six separate variables-D $v, s, p, l$, and $z$-are involved in making the foregoing calculations, five of which must be known in order to solve for the sixth. The determination of the precise values and proper units of these five known quantities sometimes involves difficulties, and it seems desirable to outline the best procedure for determining them in any given case, and to present certain data and conversion charts which will aid in the solution of practical problems.

$V i s c o s i t y-F$ or use throughout this paper viscosity, $z$, is expressed in centipoises, which may be more readily visualized as the viscosity relative to water at $68^{\circ} \mathrm{F}$, at which temperature water has a viscosity of one centipoise. Data in literature are frequently expressed in poises; these results should be multiplied by 100 to give the viscosity in centipoises.

For many definite chemical compounds entirely satisfactory viscosity data are available in the literature, and data for a number of these and for some commercial oils are presented graphically in Fig. 13. For most commercial purposes, however, it is desirable to make an independent determination of the viscosity of the fluid. To determine this directly in absolute units is difficult and time consuming, but it is possible, for liquids that are distinctly more viscous than water, to employ one of the standard instruments familiar in the oil trade, such as the Saybolt Universal viscosimeter, which measures the time of efflux of a given volume of liquid. For reasons discussed in several papers by the Burenu of Standards, this does not measure the true

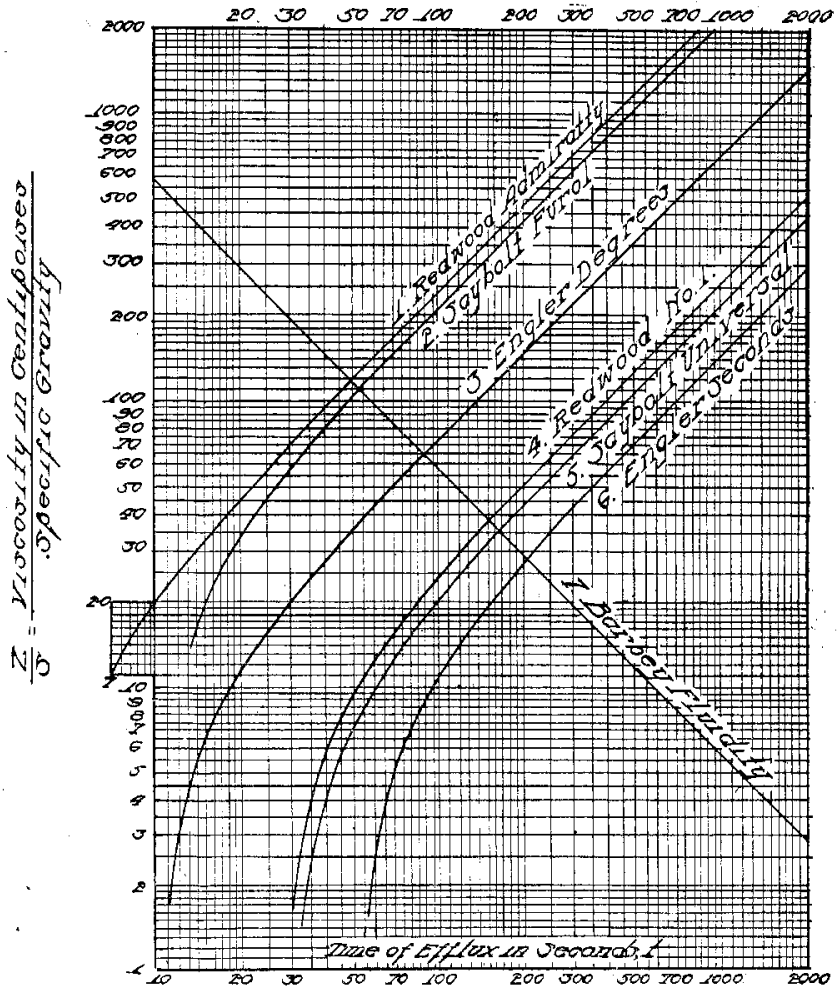

Fig. 15-Conversion Diagram Hor Viscostmeters

NOTE: For line 3, Abscissa, scale gives $10 \times$ Engler degrees $=10(t / 62)$, For line 7, Time, $t=600$, and scale gives low in $\mathrm{cc} . / \mathrm{hr}$,

viscosity directly and is not applicable to liquids having a viscosity near that of water, but by the use of the conversion charts presented in Fig. $15^{22}$ it is possible to determine the

22 Modified slightly from a chart drawn up by W. H. Herschel (Bureau of Standards). Method due to N. MacCoull, of the Texas Co. 
correct value of $\frac{z}{s}$ from the readings on any standardized type of viscosimeter. The reciprocal of this ratio may be inserted directly into the expression $\frac{\mathrm{D} v s}{z}$, or if $z$ alone is desired it can readily be obtained by multiplying this ratio by $s$, the specific gravity of the liquid at the temperature in question.

Since the same method of calculation is applicable to most problems involving the flow of gases, data are also appended (Fig. 14) for a number of common gases, including steam. It will be noted that whereas the viscosity of liquids decreases rapidly with increase in temperature, the viscosity of gases increases. It is also important to remember that the viscosity of gases is practically independent of the pressure, though of course the latter factor does affect the density, $s$, in direct proportion, and hence changes the value of $\frac{\mathrm{D} v s}{z}$, as would be expected.

It will be noted that the viscosities of the gases are far lower than those of the liquids, but it so happens that the effect is roughly counterbalanced by other factors-particularly their lower density-so that the values of $\frac{\mathrm{D} v s}{z}$ used in handling gases commercially are not far distant from those most used in the flow of liquids.

It will be noted that the data on the viscosity of various fluids are plotted on semi-logarithmic paper, which tends to give rather flat curves and makes it possible to present data on liquids whose viscosities vary greatly and yet get equal percentage accuracy in all parts of the plot. For purposes of extrapolation or of interpolation from two observed points it is preferable to use a method of plotting which gives still flatter curves, and the one which the authors recommend ${ }^{23}$ for this purpose is to plot the fluidity (the reciprocal of the viscosity) against the temperature on an ordinary scale. Most oils give nearly a straight line on this type of plot, unless they approach the point where paraffin begins to separate out or other disturbing factors enter into the determination.

Specific Gravity-The value of the specific gravity, $s$, must be expressed in units relative to water at $39^{\circ} \mathrm{F}$. (temperature of maximum density). In other words, it is equivalent to the true density in grams per cc. Specific gravity figures are frequently given relative to water at some other temperature than $39^{\circ} \mathrm{F}$. $\left(4^{\circ} \mathrm{C}\right.$.) and hence are subject to some slight correction to give the proper value of $s$ for use in the foregoing equations.

To convert Baumé readings to specific gravity use the

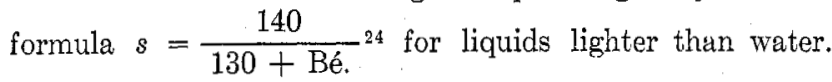

For convenience, Fig. 16 gives typical density curves for various liquids as a function of temperature, and Fig. 17 gives the same data for the commoner gases. In dealing with gases, care should be taken to use an average value if the pressure drop through the line is enough to cause appreciable variations in this factor.

Length of Pipe-This is, of course, measured in feet and the only precaution to be observed is to add to the actua] length the equivalent length of pipe due to elbows, as found by using Fig. 11. For pipes less than 500 diameters long consideration must be given to entrance and exit losses, as pointed out later under "limitations."

${ }^{23}$ More exact methods have been proposed, but are too complicated for most practical purposes.

24 While this is the official B. of S. Baumé scale, the great bulk of the oil trade uses instruments calibrated on a scale which gives 141.5 instead of 140 for this figure.
Velocity-Velocity should be expressed in ft. per sec., and means the effective average velocity in the pipe, obtained by dividing the rate of discharge in cu. ft. per sec. by the cross-sectional area of the pipe in sq. ft. Data may be transposed from gal. per min. to velocity in $\mathrm{ft}$. per sec., or vice versa, by the conversion formula, $v=\frac{0.408 \mathrm{Q}}{\mathrm{D}^{2}}$. It is also

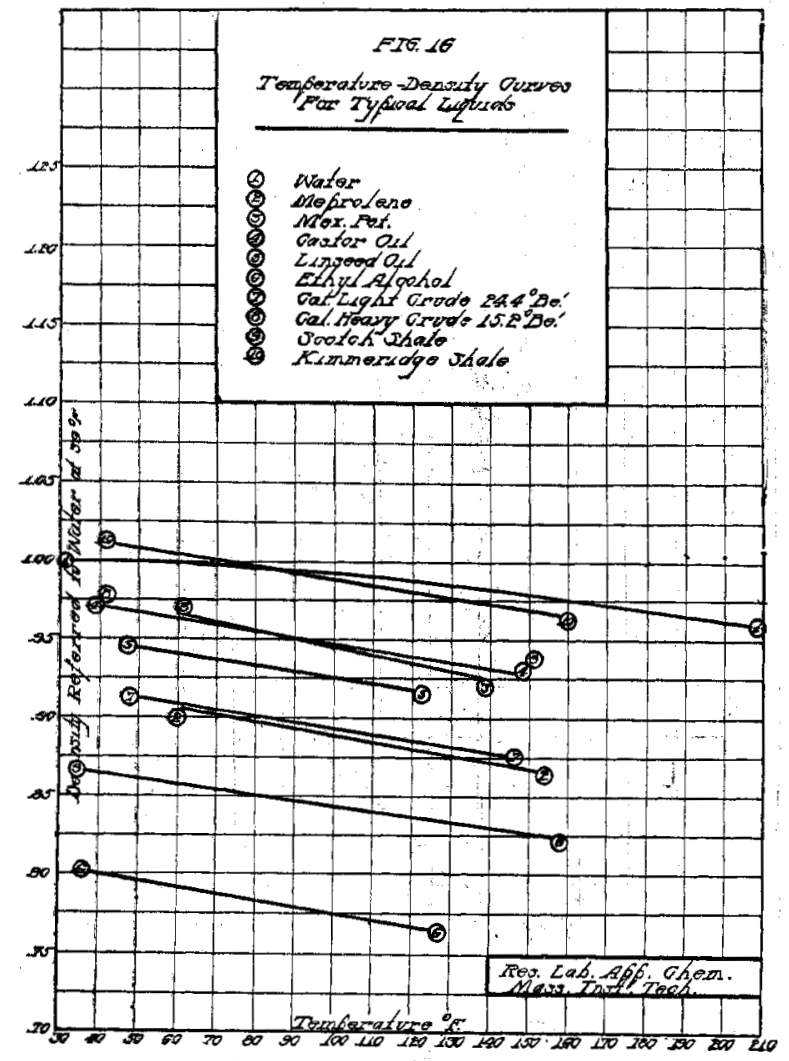

possible to use another form of Fanning's equation, which involves $Q$ instead of $v$ if any considerable number of calculations have to be made on this basis. In this case, instead of $\frac{\mathrm{D} v s}{z}$, it is necessary to calculate $\frac{0.408 \mathrm{Q} s}{\mathrm{D} z}$ and to substitute the resulting value of $f$ from Fig. 12 in the equation

$$
p=\frac{0.0538 f l s Q^{2}}{D^{5}}
$$

Pipe Diameter-The inside pipe diameter used in this: equation should be measured in inches. The nominal diam-

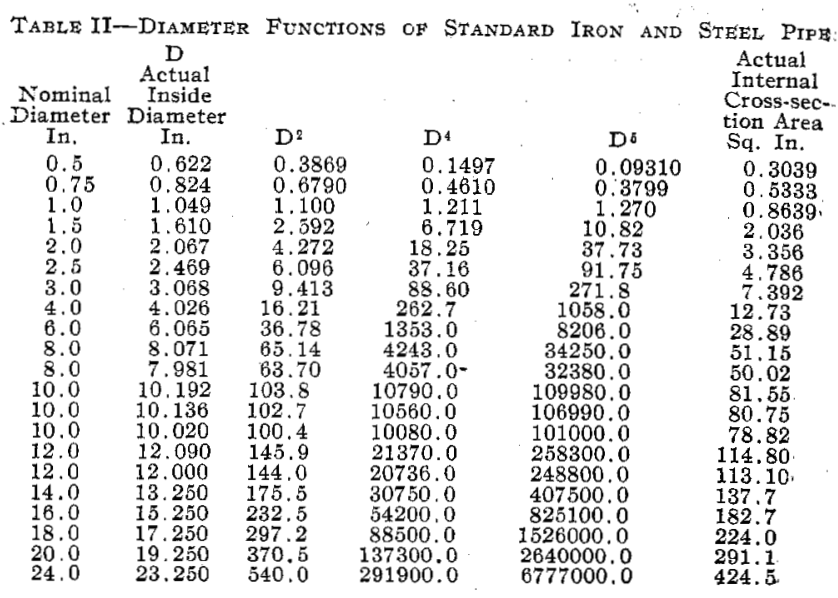


eters used to identify commercial pipes do not correspond to actual inside diameters, but their exact dimensions have been quite well standardized within recent years, and the accepted figures for each nominal size of pipe are given in Table II. For precise work the diameters should be measured accurately, as this factor enters to the fourth or fifth power in some of the equations used.

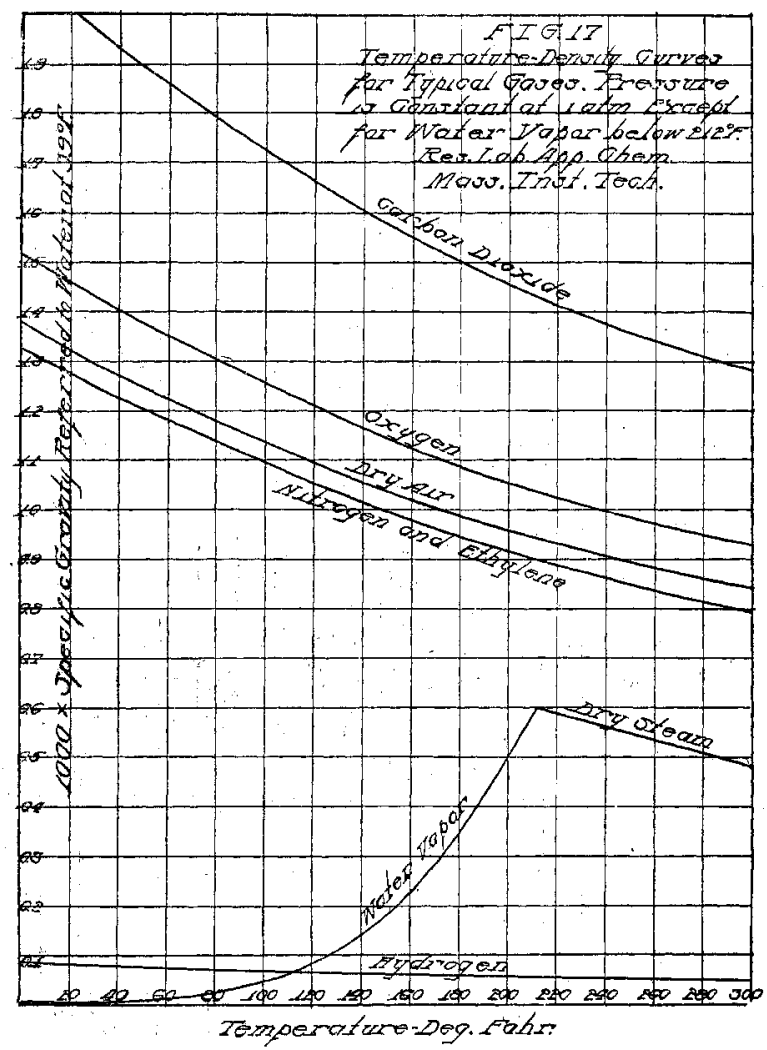

Pressure Drop-The pressure drop should be expressed in lbs. per sq. in. If the data are given in any other form they may be converted by the use of Table III. If it is desired to calculate the theoretical horse power required, the following formula can be used:

$$
\text { H. p. }=\frac{19.2 \times \text { gal. } / \mathrm{min} . \times \text { press. drop in lbs. } / \mathrm{sq} . \text { in. }}{33,000}
$$

The actual horse power required equals this figure divided by the efficiency of the pump as a whole.

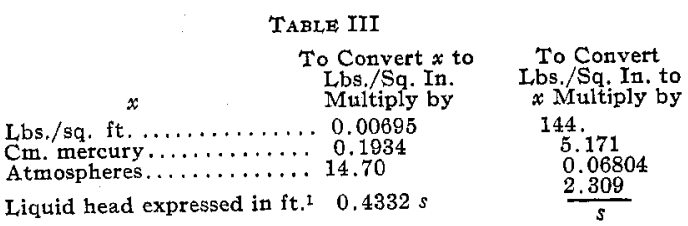

1 This equals pressure drop in lbs. per sq. ft. divided by the liquid density at that point, which $=62.3 \mathrm{~s}$.

LIMITATIONS TO APPLICATION OF RECOMMENDED METHOD OF CALCULATION-The data and methods of calculation given in this article cover substantially the entire field of the flow of all fluids, including gases and dry vapors, through commercial pipe lines. There are, however, \& few exceptions which should be carefully noted before attempting to use the formula in certain special cases. These may be specified as follows:

1-The method is not directly applicable to the flow of gases where the drop in pressure along the pipe line is more than 10 or 15 per cent of the final absolute pressure, because the density and velocity of the fluid are thereby changed. If, however, average values are used for the density and velocity, instead of the initial or final values, this formula may be used for pressure drops up to 40 or 50 per cent without serious error. To make calculations for compressed air lines with still larger drops in pressure, it is necessary to use an approximate integrated form of the equation, which has previously been discussed by Lewis. ${ }^{25}$ The regular method of calculation may, however, be used for all ordinary problems of handling air through circular ducts or steam in pipes lines.

2-The method is not applicable to flow through short sections of pipe opening into large chambers where the entrance and exit losses are appreciable in comparison with the friction losses through the pipe. These losses become inappreciable when the pipe is more than 1000 diameters long, and may generally be neglected for approximate calculations for lines longer than 300 diameters. For shorter tubes the reader is referred to the recent comprehensive treatment of Herschel. ${ }^{26}$

3-The method is not applicable to the flow of semisolid plastic materials, such as asphalt, clay suspensions, very viscous colloidal solutions, etc., where the laws of flow are modified by the tendency of the material to behave like a solid under certain conditions.

4-Precautions must be observed, and highly accurate results cannot be expected in cases: (a) where the pipe is badly corroded or tuberculated, and the apparent value of $f$ may increase to double that given in the formula, owing partly to a decrease in the effective cross-sectional area; $(b)$ where a hot oil is passing through a pipe line in straight line flow, and the existence of a large temperature gradient from the inside to the outside makes accurate calculations practically impossible; and (c) where there is any tendency to precipitate out solids (such as paraffin wax) on the walls or in the bottom of the pipe lines.

With these exceptions it is believed that the recommended method of calculation is applicable to an entirely satisfactory degree of accuracy to all commercial problems involving the flow of fluids through pipe lines.

\section{ILLTSTRATIVE ExaMples}

To illustrate the practical utilization of the foregoing charts and tables, two typical examples are appended herewith.

\section{Example 1-Calculation OF Required Pressure Drop}

It is desired to transmit 20 U.S. gal. per min. ( 686 oil bbls. per 24 hrs., based on 1 oil bbl. $=42 \mathrm{U}$.S. gal.) of a very viscous oil at $70^{\circ} \mathrm{F}$. through a standard 6-in. steel pipe line. What will be the pressure drop as Ibs. per sq. in. per mi.?

DatA-The oil at $70^{\circ} \mathrm{F}$. has a time of $9050 \mathrm{sec}$. in a Saybolt Universal viscosimeter and a gravity corresponding to $15.2^{\circ}$ Bé.

Solution-From Table II, one sees that $\mathrm{D}=6.07 \mathrm{in}$. and $\mathrm{D}^{2}=36.78$. Since the average velocity $=\frac{0.408 \mathrm{Q}}{\mathrm{D}^{2}}, v=\frac{0.408 \times 20}{36.78}=0.222 \mathrm{ft}$. per sec.

From Fig. 15 it is seen that the value of $\frac{z}{s}$, corresponding to a time of 9050 Saybolt sec, is 1990 .

Hence the numerical value of

$$
\frac{\mathrm{D} \text {. } s}{z}=\frac{6.07 \times 0.222}{1090}=0.000677
$$

atd the value of $f$ corresponding (Fig. 12) is 3.06 (extrapolation made by multiplying ordinate and dividing abscissae scales by 10 ).

The specific gravity at $70^{\circ} \mathrm{F} .=\frac{140}{130+15.2}=0.964$.

The value of $p$ is figured from the modified Fanning equation:

$$
\begin{aligned}
p=\frac{0.323 \mathrm{fls} v^{2}}{\mathrm{D}} & =\frac{0.323 \times 3.06 \times 5.280 \times 0.964 \times 0.222^{2}}{6.07} \\
& =40.8 \mathrm{lbs} . \text { per sq. in. } 7 \mathrm{~g}^{\circ}
\end{aligned}
$$

Thus it is found that this oil flowing at an average velocity of $0.222 \mathrm{ft}$. per sec, gives a pressure drop of $41 \mathrm{lbs}$. per sq. in. per mi.

$$
\text { Exampie 2-Calculation of Diameter RequTRzD }
$$

Dry compressed air at $80^{\circ} \mathrm{F}$. must be delivered through $200 \mathrm{ft}$. of straight steel pipe connerted by means of three standard elbows at a rate equivalent

25 ThIS JOURNAL, 8 (1916), 1133.

26 "The Flow of Liquids through Short Tubes," Proc.'Am. Soc. Civil Eng., 84 (1921), 527 
to 1000 en. 4 . of "frese" air per milat. The initial air is at pressure of 150 lbs. per sq, in. What size of stowdard steel pipe must be used in order that the drop in pressure shall not exceed $10 \mathrm{lbs}$, per sq. in.?

Solution-from Fig. $14, s=0.0188$ at $80^{\circ} \mathrm{F}$.

From Fig. $17, S=0.00118$ at $80^{\circ} F$, and 1 atm. Since the aversge pressure is $\frac{150+140}{2 \times 14.7}=9.87$ atm., $s=0.87 \times 0.00118=0.01165$.

Since free air refers to air at 1 atm. and $70^{\circ} \mathrm{F}$. the actual volume at $80^{\circ} \mathrm{F}$. ( $\left(540^{\circ} \mathrm{F}\right.$. absolute) amd $9.87 \mathrm{~atm}$. pressure is

$$
\frac{1000 \times 540}{9.87 \times 530}=103.2 \mathrm{ca} . \text { ft. per min., }
$$

and $v=\frac{103.2 \times 144}{60 \times 0.785 \mathrm{D}^{2}}=\frac{315}{\mathrm{D}^{2}} \mathrm{ft}$. per sec, at $80^{\circ} \mathrm{F}$. and a mean pressure of 9.87 atm.

$$
\text { Then } \frac{\mathrm{D} y s}{\mathrm{z}}=\frac{\mathrm{D} \times \frac{315}{\mathrm{D}^{2}} \times 0.01165}{0.0188}=\frac{195}{\mathrm{D}} \text {. }
$$

Taking the equivalent length of each elbow as 30 pipe diameters,

$$
\begin{gathered}
1=200+\frac{3 \times 30 \mathrm{D}}{12}=200+7.5 \mathrm{D} \\
\text { But } D=\frac{0.323 f l s v^{2}}{\mathrm{D}}, \\
\text { so }=\frac{0.323 f[200+7.5 \mathrm{D}] 0.01165 \times(315)^{2}}{\mathrm{D}^{5}} \\
\phi= \\
=\frac{374 f[200+7.5 \mathrm{D}]}{\mathrm{D}^{5}}=\frac{\mathrm{Lbs} .}{\mathrm{Sq} . \mathrm{in} .}
\end{gathered}
$$

As noted abowe, one may assume a value of $D$ actually obtainoble, find from Fig 12 the corresponding value of $\frac{\mathrm{D} v s}{\mathrm{~s}}$, and calculate $p$. The result of swch procedure is stown below,

$\begin{array}{cccccc}\text { Nominal } & \text { Actual } & \begin{array}{c}\text { D } v \\ \text { (From }\end{array} & \begin{array}{c}f \\ \text { (From } \\ \text { Fig. }\end{array} & \begin{array}{c}\text { Ds } \\ \text { (Table }\end{array} & \begin{array}{c}p \\ \text { (From }\end{array} \\ \text { Dia. } & \text { Dia. (D) } & \text { Eq. a) } & \text { 12) } & \text { II) } & \text { Eq. b) } \\ 1.5 & 1.61 & 1211 & 0.0041 & 10.82 & 30.1 \\ 2 & 2.07 & 94.3 & 0.0043 & 37.7 & 9.2\end{array}$

1 The friction factor for this case was taken from Fig. 10, as Fig. 12 does not show $f$ for values of $\frac{\mathrm{D} v s}{\mathrm{z}}$ beyond 100 .

It should be noted that although the first trial diameter $(1.61 \mathrm{in.})$ called for a pressure drop of $30 \mathrm{lbs}$. per sq. in., a diameter only slightly larger (2.07 in.) gave practically the desired pressure drop. This is because $p$ varies inversely as the fifth power of diameter. Hence a 2-in. standard steel pipe must be used to meet the specified conditions.

\section{ACKNOWLEDGMENT}

In conclusion the writers desire to express their appreciation of the many helpful suggestions of Dr. W. K. Lewis, at whose instigation this work was first undertaken; of the accurate work of Mr. V. V. Kendall, who aided in the conduction and direction of much of the experimental work; and of that of Messrs. Kite and Kennedy, who made the runs: in the turbulent and critical flow regions. Acknowledgments: are also due to the various coöperating companies mentionedl in the introduction; and to Mr. R. S. Danforth of The Kinney Manufacturing Company, and Dr. W. H. Herschel of the Bureau of Standards, for valuable suggestions.

\title{
The Determination of Carbon Dioxide in Baking Powder ${ }^{1,2}$
}

\section{By C. S. Robinson ${ }^{3}$ and Selma L. Bandemer}

\author{
Michigan Agricultural Colifge Experiment Station, East Lansing, Michigan
}

The gasometric method for the determination of carbon dioxide in baking powder is as accurate as the absorption methods. It is much more rapid and requires but a single piece of apparatus. It can be used for the determination of both total and residual carbon dioxide.

At the 1920 meeting of the Association of Official Agricultural Chemists the senior author suggested, as a substitute for the present official methods for determining total carbon dioxide in baking powder, a modification of the gasometric method originally devised by Van Slyke for the determination of carbon dioxide in blood plasma. ${ }^{4}$

Its use has since been extended to the estimation of residual carbon dioxide. The object of the present paper is to describe this procedure and report the results obtained with it.

\section{PROCEDURE}

TOTAL CARBON DIOXIDE-The procedure for the determination of total carbon dioxide in baking powder is identical with that for the analysis of marl and limestone as given in the original description of the method, except that $100-\mathrm{mg}$. samples are used.

RESIDUAL CARBON DIOXIDE-A 2-g. sample of the wellmixed material is weighed into a small beaker and $20 \mathrm{cc}$. of distilled water are added. The mixture is thoroughly stirred, allowed to stand for $20 \mathrm{~min}$. at room temperature, and set in a bath of boiling water for the same length of time. Fi-

1 Received November 3, 1921.

2 Published as Journal Article No. 20 from the Chemical Laboratory of the Michigan Agricultural College Experiment Station. Published by permission of the Director of the Experiment Station.

8 Research Associate in Chemistry.

4 J. Biol. Chem., 30 (1917), 347; Soil Sci., 10 (1920), 41 nally it is boiled for $1 \mathrm{~min}$. The addition of a drop or two of octyl alcohol to reduce foaming is sometimes advisable at this point. One sample is diluted to $25 \mathrm{cc}$. in a volumetric flask, and 1-cc. samples are used for the determination.

The accompanying table shows the results obtained with this method and with the two official methods. They are typical of the agreement of results which have been obtained in this laboratory with all sorts of carbonates during the past year.

COMParison OF OFFICIAL and Gasometric MeThods FOR DETERMINING CARBON DIOXIDE IN BAKING POWDER

$$
\text { Total Carbon Dioxide }
$$

$\begin{array}{llllll}\text { Official method } \quad 43.34 & 13.54 & 13.48 & 16.73 & 14.62\end{array}$

$\begin{array}{lllll}43.81 & 13.29 & 13.11 & 17.03 & 14.35 \\ 43.70 & 13.30 & 13.48 & 16.90 & 14.29\end{array}$

$\begin{array}{lllll}43.78 & 13.55 & 13.34 & 17.03 & 14.52\end{array}$

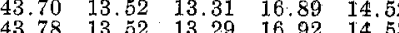

Residual Carbon Dioxide

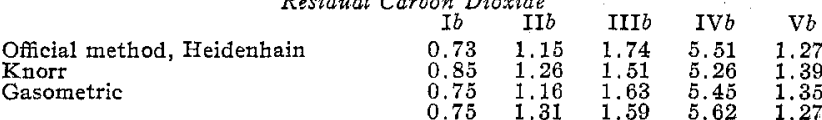

\begin{tabular}{lllll}
0.75 & 1.31 & 1.59 & 5.45 & 1.35 \\
\hline
\end{tabular}

In order to test the method when a product contained a water-insoluble carbonate, Sample IVb was made up by mixing Sample $V b$ and calcium carbonate. "Duplicate results agreed as closely as did those with other products.

Only one source of trouble has been encountered. It has been found necessary to lubricate the stopcocks of the apparatus rather frequently with a heavy grease to prevent leakage during the maintenance of the high vacuum used. If the carbon dioxide is absorbed each time and the residual air measured instead of being calculated from the table, this source of error is avoided. With proper attention to stopcocks, however, this is unnecessary. 